\title{
The ALMA-PILS survey: complex nitriles towards IRAS 16293-2422
}

\author{
H. Calcutt ${ }^{1}$, J. K. Jørgensen ${ }^{1}$, H. S. P. Müller ${ }^{2}$, L. E. Kristensen ${ }^{1}$, A. Coutens ${ }^{3}$, T. L. Bourke ${ }^{4}$, R. T. Garrod ${ }^{5}$, \\ M. V. Persson ${ }^{6}$, M. H. D. van der Wiel ${ }^{7}$, E. F. van Dishoeck ${ }^{8,9}$, and S. F. Wampfler ${ }^{10}$ \\ ${ }^{1}$ Centre for Star and Planet Formation, Niels Bohr Institute \& Natural History Museum of Denmark, University of Copenhagen, \\ Øster Voldgade 5-7, 1350 Copenhagen K., Denmark \\ e-mail: calcutt@nbi.ku.dk \\ 2 I. Physikalisches Institut, Universität zu Köln, Zülpicher Str. 77, 50937 Köln, Germany \\ ${ }^{3}$ Laboratoire d'Astrophysique de Bordeaux, Univ. Bordeaux, CNRS, B18N, allée Geoffroy Saint-Hilaire, 33615 Pessac, France \\ ${ }^{4}$ SKA Organization, Jodrell Bank Observatory, Lower Withington, Macclesfield, Cheshire SK11 9DL, UK \\ 5 Departments of Chemistry and Astronomy, University of Virginia, Charlottesville, VA 22904, USA \\ 6 Department of Space, Earth and Environment, Chalmers University of Technology, Onsala Space Observatory, \\ 43992 Onsala, Sweden \\ 7 ASTRON, The Netherlands Institute for Radio Astronomy, Postbus 2, 7990 AA Dwingeloo, The Netherlands \\ 8 Leiden Observatory, Leiden University, PO Box 9513, 2300 RA Leiden, The Netherlands \\ 9 Max-Planck Institut für Extraterrestrische Physik (MPE), Giessenbachstr. 1, 85748 Garching, Germany \\ 10 Center for Space and Habitability (CSH), University of Bern, Sidlerstrasse 5, 3012 Bern, Switzerland
}

Received 13 November 2017 / Accepted 24 April 2018

\begin{abstract}
Context. Complex organic molecules are readily detected in the inner regions of the gaseous envelopes of forming protostars. Their detection is crucial to understanding the chemical evolution of the Universe and exploring the link between the early stages of star formation and the formation of solar system bodies, where complex organic molecules have been found in abundance. In particular, molecules that contain nitrogen are interesting due to the role nitrogen plays in the development of life and the compact scales such molecules have been found to trace around forming protostars.

Aims. The goal of this work is to determine the inventory of one family of nitrogen-bearing organic molecules, complex nitriles (molecules with a $-\mathrm{C} \equiv \mathrm{N}$ functional group) towards two hot corino sources in the low-mass protostellar binary IRAS 16293-2422. This work explores the abundance differences between the two sources, the isotopic ratios, and the spatial extent derived from molecules containing the nitrile functional group.

Methods. Using data from the Protostellar Interferometric Line Survey (PILS) obtained with ALMA, we determine abundances and excitation temperatures for the detected nitriles. We also present a new method for determining the spatial structure of sources with high line density and large velocity gradients - Velocity-corrected INtegrated emission (VINE) maps.

Results. We detect methyl cyanide $\left(\mathrm{CH}_{3} \mathrm{CN}\right)$ as well as five of its isotopologues, including $\mathrm{CHD}_{2} \mathrm{CN}$, which is the first detection in the interstellar medium (ISM). We also detect ethyl cyanide $\left(\mathrm{C}_{2} \mathrm{H}_{5} \mathrm{CN}\right)$, vinyl cyanide $\left(\mathrm{C}_{2} \mathrm{H}_{3} \mathrm{CN}\right)$, and cyanoacetylene $\left(\mathrm{HC}_{3} \mathrm{~N}\right)$. We find that abundances are similar between IRAS 16293A and IRAS 16293B on small scales except for vinyl cyanide which is only detected towards the latter source. This suggests an important difference between the sources either in their evolutionary stage or warm-up timescales. We also detect a spatially double-peaked emission for the first time in molecular emission in the A source, suggesting that this source is showing structure related to a rotating toroid of material.

Conclusions. With high-resolution observations, we have been able to show for the first time a number of important similarities and differences in the nitrile chemistry in these objects. These illustrate the utility of nitriles as potential tracers of the physical conditions in star-forming regions.
\end{abstract}

Key words. stars: formation - stars: protostars - ISM: molecules - ISM: individual objects: IRAS 16293-2422

\section{Introduction}

Complex organic molecules have been detected in every environment associated with star formation. They are found at every stage, from prestellar cores, to low-mass hot corinos (e.g. Jiménez-Serra et al. 2016) and high-mass hot cores (e.g. Favre et al. 2017; Isokoski et al. 2013), right through to protoplanetary disks (e.g. Öberg et al. 2015; Walsh et al. 2016). Their detection is critical to understanding the chemical development of star-forming regions and exploring the link between the early stages of star formation and the formation of solar system bodies, where complex organic molecules have been found in abundance.
Of particular interest to such studies is the detection of complex organic molecules containing nitrogen. They are significant due to the importance nitrogen plays in the development of life (Powner et al. 2009), as well as studies of fractionation, where the largest isotopic anomalies in the solar system are found in highly volatile elements such as nitrogen (e.g. Mumma \& Charnley 2011; Wampfler et al. 2014). The spectra of star-forming regions are rich in nitrogen-bearing molecules, such as methyl cyanide $\left(\mathrm{CH}_{3} \mathrm{CN}\right)$, ethyl cyanide $\left(\mathrm{C}_{2} \mathrm{H}_{5} \mathrm{CN}\right)$ and isocyanic acid ( $\left.\mathrm{HNCO}\right)$. Methyl cyanide is considered a typical disk tracer in high-mass star formation (Cesaroni et al. 2017), owing to its excitation in very dense regions (Beltrán et al. 2005). 
In recent years it has become easier to take an inventory of the complex molecular content of star-forming regions at high angular and spectral resolution, providing an overview of the chemical evolution that occurs when a star forms. The Atacama Large Millimeter/submillimeter Array (ALMA) has been an indispensable tool in this effort, with its high sensitivity, angular resolution and spectral resolution capabilities, providing data which are orders of magnitude more sensitive than previous studies, on solar system scales (e.g. Jørgensen et al. 2016). In this work we use ALMA observations from the Protostellar Interferometric Line Survey ${ }^{1}$ (PILS) of the protostellar binary IRAS 16293-2422 (hereafter IRAS 16293) to study nitriles. IRAS 16293 is a Class 0 solar-type protostar, which is often considered the best astrochemical testbed for low-mass star formation (see e.g. van Dishoeck et al. 1995; Ceccarelli et al. 2000; Schöier et al. 2002) due to its very bright line emission and relatively close location (120 pc; Loinard et al. 2008) in the Ophiuchi star-forming complex; it consists of at least two protostars, A and B, separated by about $5^{\prime \prime}$ (600 AU), which have been observed to be rich in complex organic molecules (Bottinelli et al. 2004; Kuan et al. 2004; Bisschop et al. 2008; Jørgensen et al. 2011). Continuum observations in ALMA bands 3, 6, and 7 show clear elongated emission towards IRAS 16293A in the direction of the reported velocity gradient in this source (Pineda et al. 2012), making it appear as a flattened edge-on rotating structure (Jørgensen et al. 2016). Source B conversely exhibits a near face-on structure evident in both its continuum emission and the narrow line widths observed in its spectra without clear velocity gradients indicative of rotation, with infall signatures observed towards the peak continuum position in several molecules (Chandler et al. 2005; Pineda et al. 2012).

Several nitrogen-bearing molecules have been studied previously in this source, with both single dish and interferometric observations. Interferometric observations of $\mathrm{HNCO}$ and $\mathrm{CH}_{3} \mathrm{CN}$ emission were analysed by Bisschop et al. (2008) to explore excitation properties and spatial distributions. They found the molecular emission was compact towards both sources, with the bulk of emission originating from IRAS 16293A. They also detected $\mathrm{CH}_{3}{ }^{13} \mathrm{CN}$ in both sources to determine the ${ }^{12} \mathrm{C} /{ }^{13} \mathrm{C}$ ratio. Severe line blending in the A source made determining accurate line-intensities difficult; however, blending in the $\mathrm{B}$ source was less severe resulting in a $\mathrm{CH}_{3} \mathrm{CN} / \mathrm{CH}_{3}{ }^{13} \mathrm{CN}$ ratio of $\sim 10$. This low value compared to the local interstellar medium (ISM) value ( 70; Milam et al. 2005) was attributed to $\mathrm{CH}_{3} \mathrm{CN}$ emission being optically thick.

Jaber et al. (2017) also explored nitrogen-bearing molecules in IRAS 16293 using single-dish observations from the TIMASS survey (Caux et al. 2011). They took a census of the cyanopolyynes (species of the form $\mathrm{HC}_{n} \mathrm{~N}$ ) in this source to examine how their abundance varies across the protostellar envelope. This led to the first detection of $\mathrm{DC}_{3} \mathrm{~N}$ in a solar-type protostar. A number of first detections of nitrogen-bearing molecules have also occurred using the PILS dataset. Ligterink et al. (2017) detected methyl isocyanate $\left(\mathrm{CH}_{3} \mathrm{NCO}\right)$ and Coutens et al. (2016) detected three singly deuterated forms of formamide $\left(\mathrm{NH}_{2} \mathrm{CDO}\right.$, cis-NHDCHO, trans-NHDCHO) and deuterated isocyanic acid (DNCO) for the first time in the ISM. Cyanamide $\left(\mathrm{NH}_{2} \mathrm{CN}\right)$ was also detected for the first time in a solar-type protostar by Coutens et al. (2018).

In this work, we focus on one family of nitrogen-bearing molecules, the nitriles. Nitriles are any organic compound that contains the $-\mathrm{C} \equiv \mathrm{N}$ functional group. Their abundance in

1 http://youngstars.nbi.dk/PILS/ star-forming regions offers the opportunity to detect multiple nitrile molecules, highlighting important differences in the chemistry of these related molecules. Their detection is also important in understanding prebiotic chemistry. Simple nitriles, such as $\mathrm{HCN}$, are key precursors to the prebiotic synthesis of RNA and DNA (Banerjee et al. 2014). More complex nitriles, such as vinyl cyanide $\left(\mathrm{C}_{2} \mathrm{H}_{3} \mathrm{CN}\right)$, have also been suggested as the building blocks of non-terrestrial cell membranes capable of forming and functioning in liquid methane at cryogenic temperatures (Stevenson et al. 2015), highlighting their significance in astrobiology as well as astrochemistry.

We present the most detailed study of nitriles in IRAS 16293 to date, exploring the chemistry in both sources A and B to explore the excitation, abundance, and spatial scale of this family of organics. In Sect. 2, the observations used for the analysis are described, in Sect. 3 the analysis methodology and the results from this work are presented, and the significance of this work is discussed in Sect. 4. A summary and conclusions are presented in Sect. 5.

\section{Observations}

ALMA observations taken as part of the PILS program (Jørgensen et al. 2016) are used for the analysis in this work. The data are a combination of $15 \mathrm{~h}$ of observations with the main array (typically 36-41 antennas in the array at the time of observations) and $30 \mathrm{~h}$ of observations with the Atacama Compact Array (ACA; typically 8-10 antennas) in band 7, between $329.147 \mathrm{GHz}$ and $362.896 \mathrm{GHz}$. The combined dataset analysed in this paper was produced with a circular restoring beam of $0 . .5$ at a spectral resolution of $0.2 \mathrm{~km} \mathrm{~s}^{-1}$ and an RMS of about 7-10 $\mathrm{mJy}_{\text {beam }}^{-1}$ channel $^{-1}$, that is, approximately $4-5 \mathrm{mJy}^{-1} \mathrm{bem}^{-1} \mathrm{~km} \mathrm{~s}^{-1}$. Further details of the data reduction and continuum subtraction procedure can be found in Jørgensen et al. (2016).

The spectral analysis presented in this work is performed towards two positions, at $\alpha_{J 2000}=16^{\mathrm{h}} 32^{\mathrm{m}} 22^{\mathrm{s}} .58$, $\delta_{J 2000}=-24^{\circ} 28^{\prime} 32^{\prime \prime} .8$ and $\alpha_{J 2000}=16^{\mathrm{h}} 32^{\mathrm{m}} 22^{\mathrm{s}} .90, \delta_{J 2000}=$ $-24^{\circ} 28^{\prime} 36^{\prime \prime}$. 2 . The first position is offset by one beam diameter $(0 " .5,60 \mathrm{AU})$ from the continuum peak position of IRAS $16293 \mathrm{~B}$ in the south west direction. This position is used as the lines are particularly bright, do not have strong absorption features towards the bright continuum of IRAS 16293B, and do not suffer from high continuum optical depth (Coutens et al. 2016; Lykke et al. 2017). The second position is offset by 0."6 (68 AU) north east from the peak continuum position. The full width at half maximum (FWHM) of lines around IRAS 16293A are much broader than around IRAS $16293 \mathrm{~B}$, particularly at the peak continuum emission position $\left(3 \mathrm{~km} \mathrm{~s}^{-1} \mathrm{vs} 1 \mathrm{~km} \mathrm{~s}^{-1}\right)$. This makes line blending a significant problem for identification and analysis of molecular emission. At the IRAS 16293A offset position, however, the typical FWHM is $2.2 \mathrm{~km} \mathrm{~s}^{-1}$, which minimises line blending issues, but is still close enough to the peak position to detect weaker isotopologues. Both these positions are indicated with a white cross in the left panel of Fig. 1, as well as the continuum peak position for both sources, which is indicated with a red star. The right panel of Fig. 1 shows the typical FWHM of IRAS 16293A at the continuum peak position and the offset position.

\section{Results and analysis}

The spectra extracted from both sources A and B have been searched for complex nitrogen-bearing organics. To determine 


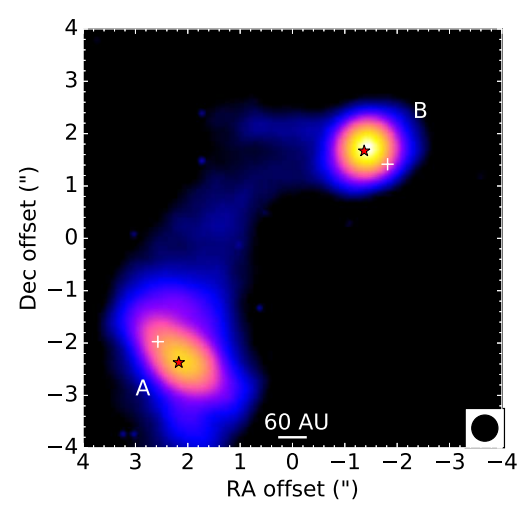

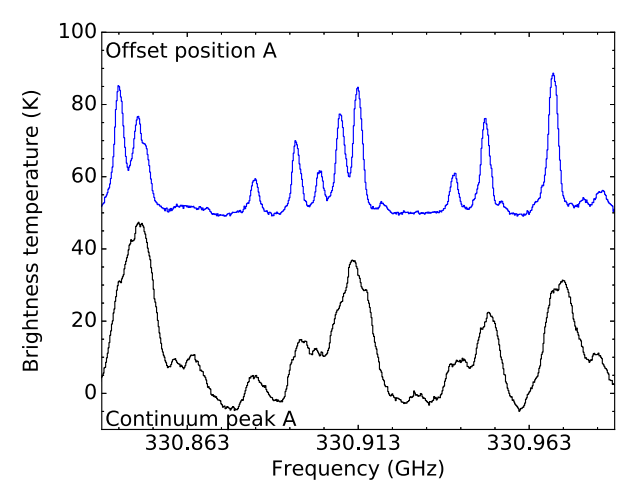

Fig. 1. Left panel: band $7(0.87 \mathrm{~mm})$ continuum image of IRAS 16293 with the peak continuum positions marked with red stars and the offset positions analysed in this work marked with white crosses. Right panel: spectra towards the continuum peak position of source $\mathrm{A}$ (black line) and the offset position (blue line) analysed in this work. abundances and excitation temperatures, the spectral modelling software CASSIS $^{2}$ was used to compute the best fit spectral models to the observations, assuming local thermodynamic equilibrium (LTE). Line lists for each of the molecules discussed in this work were taken from the CDMS catalogue ${ }^{3}$. The $\mathrm{CH}_{3}^{13} \mathrm{CN}$, ${ }^{13} \mathrm{CH}_{3} \mathrm{CN}$ and $\mathrm{CH}_{3} \mathrm{C}^{15} \mathrm{~N}$ entries are based on Müller et al. (2009) with additional data in the range of our survey from Pearson \& Müller (1996). The $\mathrm{CH}_{2} \mathrm{DCN}$ and $\mathrm{CHD}_{2} \mathrm{CN}$ entries are based on Nguyen et al. (2013) with additional data from Le Guennec et al. (1992) and Müller et al. (2009) for $\mathrm{CH}_{2} \mathrm{DCN}$ and from Halonen \& Mills (1978) for $\mathrm{CHD}_{2} \mathrm{CN}$. Vibrational corrections were taken from the main isotopic species (Müller et al. 2015); differences among the isotopic species can be neglected at the excitation temperatures of the species presented in this work.

The ethyl cyanide entry is based on Brauer et al. (2009) with additional important contributions from Fukuyama et al. (1996) and Pearson et al. (1994). Vibrational correction factors to the partition function are provided in the CDMS; they are 1.32 and 1.46 for 140 and $160 \mathrm{~K}$, respectively (Heise et al. 1981). The cyanoacetylene entry is based on Thorwirth et al. (2000) with important additional contributions, also in the range of our survey, from Yamada et al. (1995). Vibrational correction factors are 1.09 and 1.38 at 100 and $160 \mathrm{~K}$, respectively (Mallinson \& Fayt 1976). The vinyl cyanide entry was taken from the CDMS. It is based on Müller et al. (2008) with additional data in the range of our survey from Demaison et al. (1994). Numerous low-lying excited vibrational states were taken into account in the calculation of the partition function (Khlifi et al. 1999 and H. S. P. Müller, unpublished). The correction factor is 1.17 at $150 \mathrm{~K}$.

A large grid of models was run to determine the best fit excitation temperature, FWHM, velocity peak $V_{\text {peak }}$, and column density for each molecule. Excitation temperatures of 90$300 \mathrm{~K}$ are explored for both sources. A FWHM in the range $1.8-2.4 \mathrm{~km} \mathrm{~s}^{-1}$ for the A source and $0.8-1.2 \mathrm{~km} \mathrm{~s}^{-1}$ for the $\mathrm{B}$ source is explored. A $V_{\text {peak }}$ in the range $0.6-0.8 \mathrm{~km} \mathrm{~s}^{-1}$ for the A source, based on the observed velocity shift at the offset position for source A of $0.8 \mathrm{~km} \mathrm{~s}^{-1}$ is explored. For the B source a $V_{\text {peak }}$ in the range $2.5-2.9 \mathrm{~km} \mathrm{~s}^{-1}$ is explored, based on the $V_{\mathrm{LSR}}$ of $2.7 \mathrm{~km} \mathrm{~s}^{-1}$ for source B. Column densities in the range of $1 \times 10^{13}-1 \times 10^{17} \mathrm{~cm}^{-2}$ are explored. The reduced $\chi^{2}$ minimum is then computed to determine the best fit model, assuming a source size of $0 . " 5$ determined from emission maps (see Fig. 5). The significant spectral density seen in IRAS 16293 means that line blending is an issue within the spectra for both sources A and B. Significantly blended lines

\footnotetext{
http: //cassis.irap.omp.eu/

http://wWw . astro.uni-koeln.de/cdms
}

(lines which fail the Rayleigh criterion, where the minimum distance between two spectral lines must be such that the maximum intensity of one line falls on the first minimum of the other line, Snyder et al. 2005), are excluded from the best fit model calculations. Optically thick lines are also a problem for some of the species modelled, and therefore only optically thin lines $(\tau<0.2)$ are used to determine the best fit model.

Due to the strong continuum reported towards IRAS 16293, the continuum component is included in the spectral model as a background temperature component. Since the continuum is dominated by the high-column-density dust in the disk while the lines arise from the infalling gas in the envelope, the dust and gas are not fully coupled at the positions analysed in this work. The correction is calculated as in Jørgensen et al. (2016) and is 1.14 at $125 \mathrm{~K}$ towards the $\mathrm{B}$ position and 1.24 at $125 \mathrm{~K}$ towards the A position.

The main sources of error for the column density and excitation temperatures are from the quality of the fit of the spectral model to the data, which relies on the assumption of LTE, optically thin emission, and Gaussian profiles. This is a particular problem for species with a number of optically thick lines, which had to be excluded from the fit, and therefore a lower number of lines were available to constrain the fitted parameters. We estimate the errors, based on varying the $N_{\text {tot }}$ and $T_{\text {ex }}$ to determine the impact this has on the fit of the observations.

\subsection{Column densities and excitation temperatures}

Transitions of several prominent complex nitrogen-bearing organics are detected towards both IRAS 16293A and IRAS 16293B. Table 1 shows the best-fit excitation temperatures, column densities and relative abundance for each species in each source. Lines towards IRAS 16293A are best fitted with a FWHM of $2.2 \mathrm{~km} \mathrm{~s}^{-1}$ and a $V_{\text {peak }}$ of $0.8 \mathrm{~km} \mathrm{~s}^{-1}$, except for $\mathrm{HC}_{3} \mathrm{~N}$ which is best fitted with a $V_{\text {peak }}$ of $1.2 \mathrm{~km} \mathrm{~s}^{-1}$. Lines towards IRAS 16293B are best fitted with a FWHM of $1.0 \mathrm{~km} \mathrm{~s}^{-1}$ and a $V_{\text {peak }}$ of $2.7 \mathrm{~km} \mathrm{~s}^{-1}$. The transitional information for every detection presented in this work can be found in the tables in Appendix B.

Methyl cyanide $\left(\mathrm{CH}_{3} \mathrm{CN}\right)$ is the most abundant complex nitrile detected in IRAS 16293, being at least one order of magnitude more abundant than the next most abundant cyanide, and found to be optically thick in both sources. Several transitions of the main species, both the $v=0$ state and $v=1$ excited state, are detected towards both sources, as well as several of its isotopologues: $\mathrm{CH}_{3} \mathrm{C}^{15} \mathrm{~N},{ }^{13} \mathrm{CH}_{3} \mathrm{CN}, \mathrm{CH}_{3}{ }^{13} \mathrm{CN}, \mathrm{CH}_{2} \mathrm{DCN}$, and $\mathrm{CHD}_{2} \mathrm{CN}$ (Fig. 2). The detection of the doubly deuterated form $\left(\mathrm{CHD}_{2} \mathrm{CN}\right)$ is the first detection in the ISM. To compute the excitation temperature for these species we fit the most optically 
Table 1. Excitation temperature $\left(T_{\text {ex }}\right)$, column density $\left(N_{\text {tot }}\right)$ and relative abundance determined relative to $\mathrm{CH}_{3} \mathrm{CN}$ for complex nitrogen bearing species in IRAS 16293B and IRAS 16293A.

\begin{tabular}{lccc}
\hline \hline Molecule & $T_{\text {ex }}(\mathrm{K})$ & $N_{\text {tot }}\left(\mathrm{cm}^{-2}\right)$ & $\begin{array}{c}\text { Relative } \\
\text { abundance }\end{array}$ \\
\hline & \multicolumn{3}{c}{ IRAS 16293A } \\
\hline $\mathrm{CH}_{3} \mathrm{CN}^{\dagger}$ & $120(10)$ & $8.0(1.0) \times 10^{16}$ & 1 \\
${ }^{13} \mathrm{CH}_{3} \mathrm{CN}$ & $120(10)$ & $1.0(0.2) \times 10^{15}$ & 0.013 \\
$\mathrm{CH}_{3}{ }^{13} \mathrm{CN}$ & $120(10)$ & $1.2(0.2) \times 10^{15}$ & 0.015 \\
$\mathrm{CH}_{3} \mathrm{C}^{15} \mathrm{~N}$ & $120(10)$ & $3.4(0.2) \times 10^{14}$ & 0.004 \\
$\mathrm{CH}_{2} \mathrm{DCN}$ & $120(10)$ & $3.5(0.5) \times 10^{15}$ & 0.044 \\
$\mathrm{CHD}_{2} \mathrm{CN}$ & $120(10)$ & $2.2(0.5) \times 10^{14}$ & 0.003 \\
$\mathrm{C}_{2} \mathrm{H}_{5} \mathrm{CN}$ & $140(10)$ & $9.0(0.2) \times 10^{15}$ & 0.113 \\
$\mathrm{C}_{2} \mathrm{H}_{3} \mathrm{CN}$ & $150(10)$ & $\leq 2.4 \times 10^{14 \dagger}$ & $\leq 0.002^{\dagger \dagger}$ \\
$\mathrm{HC}_{3} \mathrm{~N}$ & $160(20)$ & $4.4(0.2) \times 10^{14}$ & 0.006 \\
\hline & & IRAS $16293 \mathrm{~B}$ & \\
\hline $\mathrm{CH}_{3} \mathrm{CN}$ & $110(10)$ & $4.0(1.0) \times 10^{16}$ & 1 \\
${ }^{13} \mathrm{CH}_{3} \mathrm{CN}$ & $110(10)$ & $6.0(0.2) \times 10^{14}$ & 0.015 \\
$\mathrm{CH}_{3}{ }^{13} \mathrm{CN}$ & $110(10)$ & $5.0(0.2) \times 10^{14}$ & 0.013 \\
$\mathrm{CH}_{3} \mathrm{C}^{15} \mathrm{~N}$ & $110(10)$ & $1.6(0.2) \times 10^{14}$ & 0.004 \\
$\mathrm{CH}_{2} \mathrm{DCN}$ & $110(10)$ & $1.4(0.2) \times 10^{15}$ & 0.035 \\
$\mathrm{CHD}_{2} \mathrm{CN}$ & $110(10)$ & $2.0(0.2) \times 10^{14}$ & 0.005 \\
$\mathrm{C}_{2} \mathrm{H}_{5} \mathrm{CN}$ & $110(10)$ & $3.6(0.2) \times 10^{15}$ & 0.090 \\
$\mathrm{C}_{2} \mathrm{H}_{3} \mathrm{CN}$ & $110(10)$ & $7.4(0.2) \times 10^{14}$ & 0.019 \\
$\mathrm{HC}_{3} \mathrm{~N}$ & $100(20)$ & $1.8(0.2) \times 10^{14}$ & 0.005 \\
\hline
\end{tabular}

Notes. All models assume LTE and a source size of 0".5. Errors are given in brackets. ${ }^{\dagger}$ Derived from the $v_{8}=1$ state. ${ }^{\dagger}$ Determined for the $3 \sigma$ limit.

thin species $\left(\mathrm{CH}_{3} \mathrm{C}^{15} \mathrm{~N}\right.$ and $\left.\mathrm{CHD}_{2} \mathrm{CN}\right)$ allowing the excitation temperature to vary in the range $90-300 \mathrm{~K}$. We then performed a second fit for all methyl cyanide species to determine their column densities with a fixed excitation temperature of the average determined from the first fit. The best fit models for methyl cyanide and its isotopologues are overlaid on the spectra for the nine brightest lines in Figs. A.1-A.6. ${ }^{13} \mathrm{CH}_{3}{ }^{13} \mathrm{CN}$ is not detected towards IRAS $16293 \mathrm{~A}$ or B, however, its transitions within the observed frequency range are weak and could be obscured by line blending. The column densities of the two ${ }^{13} \mathrm{C}$ forms of methyl cyanide are similar.

Vinyl cyanide is only detected in IRAS $16293 \mathrm{~B}$ but an upper limit column density is determined towards source A, using $1.05 \times \mathrm{RMS} \times \sqrt{\Delta V \times F W H M}$ to compute the $1 \sigma$ limit, where $\Delta V$ is the spectral resolution of the data and 1.05 is a factor to account for a 5\% flux calibration uncertainty, and the FWHM used is the same as other nitriles fitted at this position $\left(2.2 \mathrm{~km} \mathrm{~s}^{-1}\right)$. An upper limit column density is then determined using a $3 \sigma$ limit for the $331.087 \mathrm{GHz}$ line of vinyl cyanide (a bright line in a relatively line free region).

Ethyl cyanide and cyanoacetylene $\left(\mathrm{HC}_{3} \mathrm{~N}\right)$ are detected in both sources. Producing a good LTE model for $\mathrm{HC}_{3} \mathrm{~N}$ was complicated by there only being three lines available in the data to model; two of which $(345.609 \mathrm{GHz}$ and $354.697 \mathrm{GHz})$ are blended with other molecules (Fig. A.9). Such blending, which is more severe towards the A source, may explain why the $V_{\text {peak }}$ determined for $\mathrm{HC}_{3} \mathrm{~N}$ in the $\mathrm{A}$ source is shifted by two channels compared to the other nitrile species, and numerous molecules from other PILS studies (Ligterink et al. 2017; Manigand et al. 2018). Alternatively, $\mathrm{HC}_{3} \mathrm{~N}$ could be partially tracing a different physical component as well as the hot corino. It is difficult to explore this further without more lines observed at high angular resolution. The column densities and excitation temperatures given in Table 1 are therefore only a best estimate. The isotopologues of these species were also searched for in both sources. Lines of $\mathrm{C}_{2} \mathrm{H}_{5}{ }^{13} \mathrm{CN}$ can be fitted to features in the spectra of IRAS 16293B; however, these features are very weak and in all cases either severely blended or very near the noise level, and hence cannot be claimed as a detection. Isotopologues of vinyl cyanide and additional isotopologues of ethyl cyanide are not detected in this work. A search for $\mathrm{HC}_{5} \mathrm{~N}$ and $\mathrm{DC}_{3} \mathrm{~N}$ were also undertaken as these species have been identified in IRAS 16293 by Jaber et al. (2017). Their transitions in the PILS dataset, however, are too weak to be detected.

\subsection{Relative abundances}

To compare the column densities presented in the previous section for each source, the abundance of each molecule is computed relative to methyl cyanide and methanol. Since the transitions of $\mathrm{CH}_{3} \mathrm{CN} v=0$ are optically thick, the total column density for methyl cyanide is derived from the column density for the excited $\left(v_{8}=1\right)$ state. For methanol, the column densities are taken from Jørgensen et al. (2016, 2017) for IRAS 16293B, and Manigand et al. in prep. for IRAS 16293A, which were both determined using column densities for $\mathrm{CH}_{3}^{18} \mathrm{OH}$ multiplied by the standard ${ }^{16} \mathrm{O} /{ }^{18} \mathrm{O}$ ISM value of 560 (Wilson \& Rood 1994).

In the top panel of Fig. 3, the abundance of each species is plotted relative to methyl cyanide for both IRAS 16293A and IRAS 16293B. In the middle and bottom panels, the relative abundance ratio between $\mathrm{A}$ and $\mathrm{B}$ are plotted with respect to methanol abundances and methyl cyanide abundances, respectively.

For methyl cyanide and its isotopologues, the relative abundances are remarkably similar between $\mathrm{A}$ and $\mathrm{B}$ with differences in the abundance ratio in the range 0.6-1.7 (see Sect. 4 for discussion). Abundances computed relative to methanol show more variation between the sources. The difference in abundance ratio between $\mathrm{A}$ and $\mathrm{B}$ for ethyl cyanide and $\mathrm{HC}_{3} \mathrm{~N}$ is also similar to the difference relative to methyl cyanide.

Vinyl cyanide is the distinct outlier among the nitriles, being at least nine times more abundant towards $\mathrm{B}$, based on an upper limit column density calculated for the $331.087 \mathrm{GHz}$ line towards source A at an excitation temperature of $150 \mathrm{~K}$. Upper-limit column densities were also computed for a range of excitation temperatures $(50-500 \mathrm{~K})$ to determine whether this striking abundance difference could be due to differences in excitation. Whilst excitation temperatures of $280 \mathrm{~K}$ did produce higher upper limit column densities for vinyl cyanide, plotting these column densities with CASSIS led to a clear overproduction of emission for some lines. We are therefore confident that the abundance differences for vinyl cyanide determined between IRAS 16293A and B are due to chemical differences and not excitation effects.

\subsection{Isotopic ratios}

The detection of several isotopologues of methyl cyanide in this work enables the computation of some isotopic ratios from the data. Since the main species of methyl cyanide is optically thick, the column density of the excited $\left(v_{8}=1\right)$ state of methyl cyanide is used to compute the ${ }^{12} \mathrm{C} /{ }^{13} \mathrm{C}$, the ${ }^{14} \mathrm{~N} /{ }^{15} \mathrm{~N}$, and the $\mathrm{D} / \mathrm{H}$ ratios in sources A and B in Table 2. 

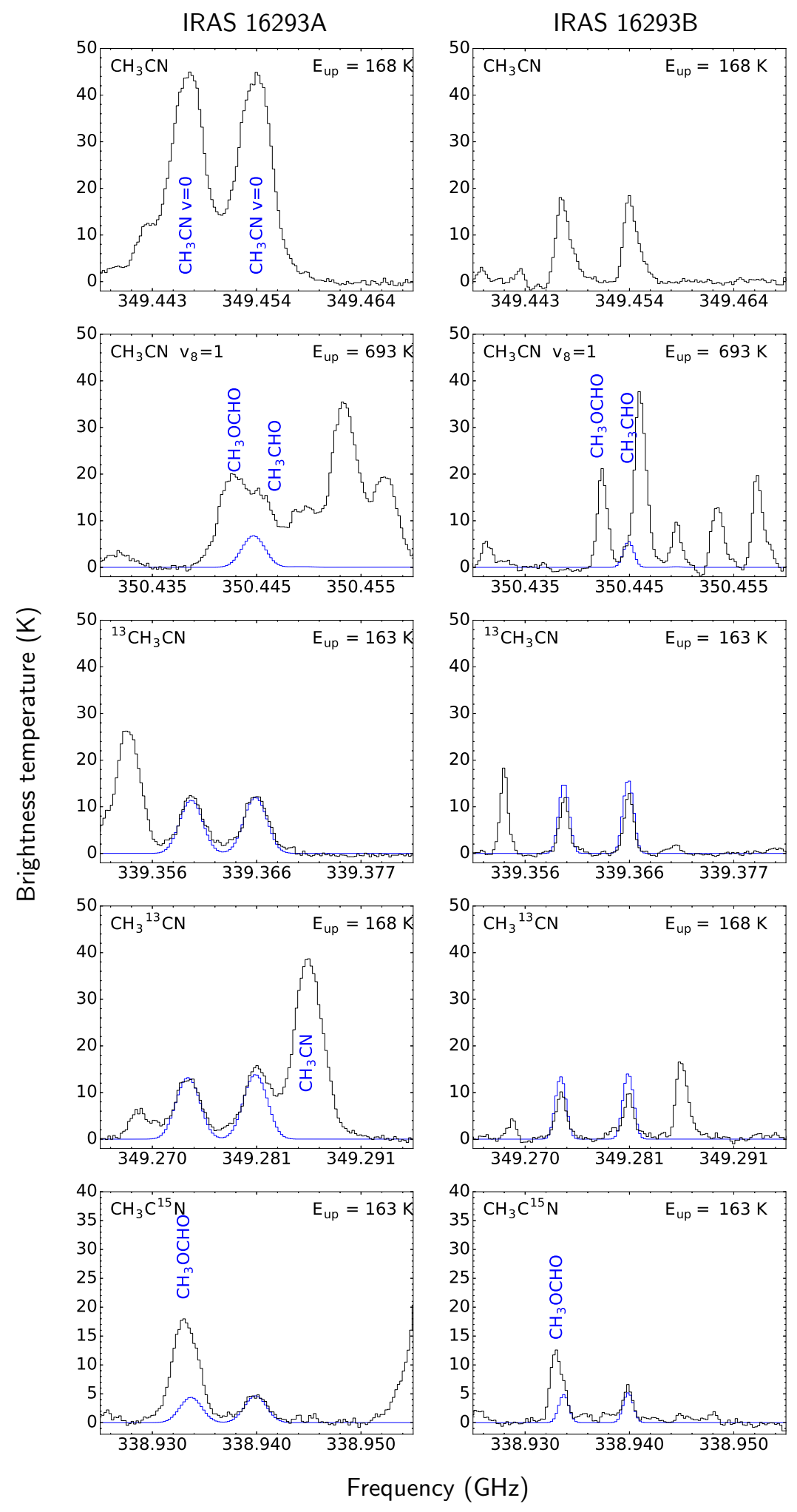

Fig. 2. Spectra of the $19_{0}-18_{0}$ line of $\mathrm{CH}_{3} \mathrm{CN}, \mathrm{CH}_{3} \mathrm{CN}$ $v_{8}=1,{ }^{13} \mathrm{CH}_{3} \mathrm{CN}, \mathrm{CH}_{3}{ }^{13} \mathrm{CN}$, and $\mathrm{CH}_{3} \mathrm{C}^{15} \mathrm{~N}$ in sources A and $\mathrm{B}$. An LTE model for each species is overlaid in blue except for $\mathrm{CH}_{3} \mathrm{CN}$ where the emission is optically thick and therefore a good fit cannot be found. Blended species are labelled in the figure.

The ${ }^{12} \mathrm{C} /{ }^{13} \mathrm{C}$ ratio is determined for both the ${ }^{13} \mathrm{CH}_{3} \mathrm{CN}$ and the $\mathrm{CH}_{3}{ }^{13} \mathrm{CN}$ isotopologues of methyl cyanide. The values towards both sources are similar to the ISM value of $68 \pm 15$ (Milam et al. 2005). The ${ }^{14} \mathrm{~N} /{ }^{15} \mathrm{~N}$ ratio is similar towards IRAS $16293 \mathrm{~A}$ and $\mathrm{B}$ to values determined from $\mathrm{HNC}$ isotopologues by Wampfler et al. (2014) towards IRAS 16293A, but higher than the value determined in the same work for HCN isotopologues and the lower limits found for formamide and $\mathrm{HNCO}$ of
100 and 138, respectively, by Coutens et al. (2016). The D/H ratio given in the table is calculated using both the column densities of $\mathrm{CH}_{2} \mathrm{DCN}$ and $\mathrm{CHD}_{2} \mathrm{CN}$, where both values have been corrected for the number of hydrogen to deuterium atoms. The values range from 1.2 to $1.5 \%$ for both sources when using singly deuterated column densities and increase to between 3.0 and $4.0 \%$ when using doubly deuterated column densities. This represents an enhancement in the $\mathrm{D} / \mathrm{H}$ ratio by a factor 

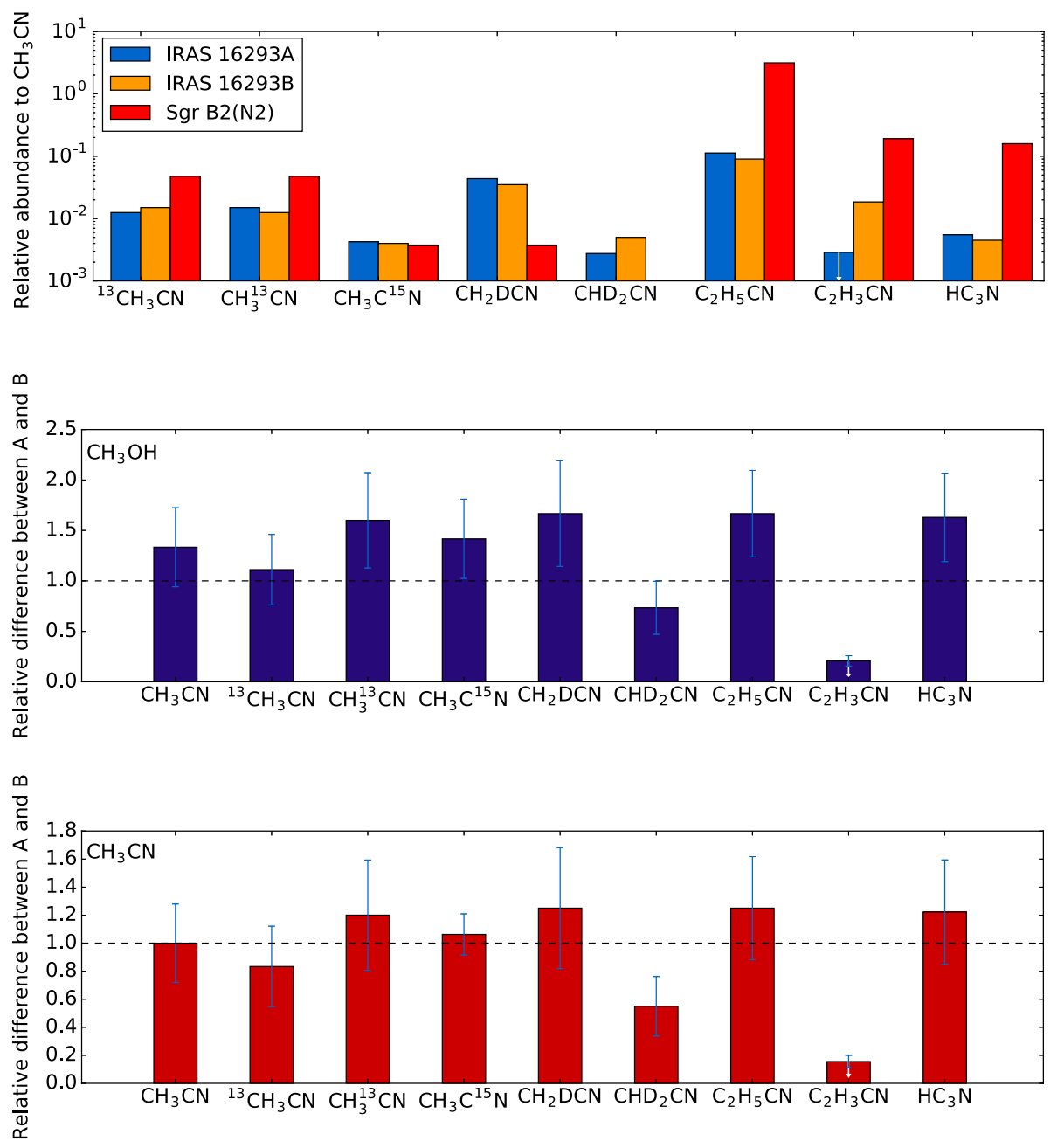

Fig. 3. Top panel: abundance of each species discussed in this work relative to methyl cyanide in IRAS 16293A and IRAS 16293B. Middle panel: relative abundance difference between $\mathrm{A}$ and $\mathrm{B}(\mathrm{X}(\mathrm{A}) / \mathrm{X}(\mathrm{B}))$ when computed relative to methanol. Bottom panel: relative abundance difference between $\mathrm{A}$ and $\mathrm{B}$ $(\mathrm{X}(\mathrm{A}) / \mathrm{X}(\mathrm{B}))$ when computed relative to methyl cyanide.
Table 2. Isotopic ratios in IRAS 16293A and B using methyl cyanide and its isotopologues.

\begin{tabular}{lcc}
\hline \hline Isotopic ratio & Source A & Source B \\
\hline${ }^{12} \mathrm{C} /{ }^{13} \mathrm{C}^{a}$ & $80 \pm 19$ & $67 \pm 17$ \\
${ }^{12} \mathrm{C} /{ }^{13} \mathrm{C}^{a}$ & $67 \pm 14$ & $80 \pm 20$ \\
${ }^{14} \mathrm{~N} /{ }^{15} \mathrm{~N}$ & $235 \pm 33$ & $250 \pm 70$ \\
$\mathrm{D} / \mathrm{H}(\mathrm{D} 1, \mathrm{D} 0)^{b}$ & $1.5 \pm 0.3 \%$ & $1.2 \pm 0.3 \%$ \\
$\mathrm{D} / \mathrm{H}(\mathrm{D} 2, \mathrm{D} 0)^{b}$ & $3.0 \pm 0.3 \%$ & $4.0 \pm 0.5 \%$ \\
\hline
\end{tabular}

Notes. ${ }^{(a)}$ The ${ }^{12} \mathrm{C} /{ }^{13} \mathrm{C}$ ratio is derived from the ${ }^{13} \mathrm{CH}_{3} \mathrm{CN} / \mathrm{CH}_{3} \mathrm{CN}$ and $\mathrm{CH}_{3}^{13} \mathrm{CN} / \mathrm{CH}_{3} \mathrm{CN}$ ratios, respectively. ${ }^{(b)}$ The $\mathrm{D} / \mathrm{H}$ ratio was derived from the $\mathrm{CH}_{2} \mathrm{DCN} / \mathrm{CH}_{3} \mathrm{CN}$ and $\mathrm{CHD}_{2} \mathrm{CN} / \mathrm{CH}_{3} \mathrm{CN}$ ratios, respectively, taking into account the statistical correction. With D1 referring to the singly deuterated form, D2 referring to the doubly deuterated form, and D0 referring to the main species.

of two in IRAS 16293A and more than a factor of three in IRAS 16293B. These $\mathrm{D} / \mathrm{H}$ values are consistent with those found for methanol, ketene, formic acid, formaldehyde, formamide, isocyanic acid, cyanamide and formaldehyde in this object with PILS data ( 2-3\%; Jørgensen et al. 2017, Coutens et al. 2016, 2018; Persson et al. 2018). Those species were also found to have a ${ }^{12} \mathrm{C} /{ }^{13} \mathrm{C}$ ratio similar to the ISM, in contrast to species with larger $\mathrm{D} / \mathrm{H}$ ratios (5-6\%; e.g. ethanol, methyl formate and glycolaldehyde), which have a lower ${ }^{12} \mathrm{C} /{ }^{13} \mathrm{C}$ ratio $(25-41 \%$; Jørgensen et al. 2017). Methyl cyanide fits in with this pattern.

\subsection{Spatial extent}

To explore the spatial extent of the molecules detected in this work we have produced emission maps for each molecule. A large velocity gradient $\left(\sim 6 \mathrm{~km} \mathrm{~s}^{-1}\right)$ is observed around IRAS $16293 \mathrm{~A}$ due to its near edge-on rotating structure (Pineda et al. 2012). This makes producing a channel map by integrating over the entire line profile for a given line difficult as it leads to contamination from other nearby molecular lines due to the range of velocities that have to be integrated over and the crowded spectra observed in hot corinos. In the past, this has limited the spatial information that can be determined for a given species around IRAS 16293A. In this paper, however, we use a new method for determining the molecular emission structure around IRAS 16293A. We use a bright transition of methanol, the $73,5-6_{4,4}$ line at $337.519 \mathrm{GHz}$, to produce a velocity map of IRAS $16293 \mathrm{~A}$ (Fig. 4, top left). Methanol was chosen because it traces the hot corino emission and has very bright lines which can be used to determine how much the peak velocity of a given line at a given pixel differs from the measured $V_{\mathrm{LSR}}$ of the source. We then use this velocity map to determine the centroid channel for a given transition in each pixel, integrating over several channels either side to cover the whole spectral profile. We choose lines that are not blended and integrate over all the channels that contain emission above the RMS of the spectra. We henceforth refer to such maps as VINE maps. Whilst velocity correction techniques have been employed in the past (Matrà et al. 2015; Marino et al. 2016; Yen et al. 2016), this method is fundamentally different, in 

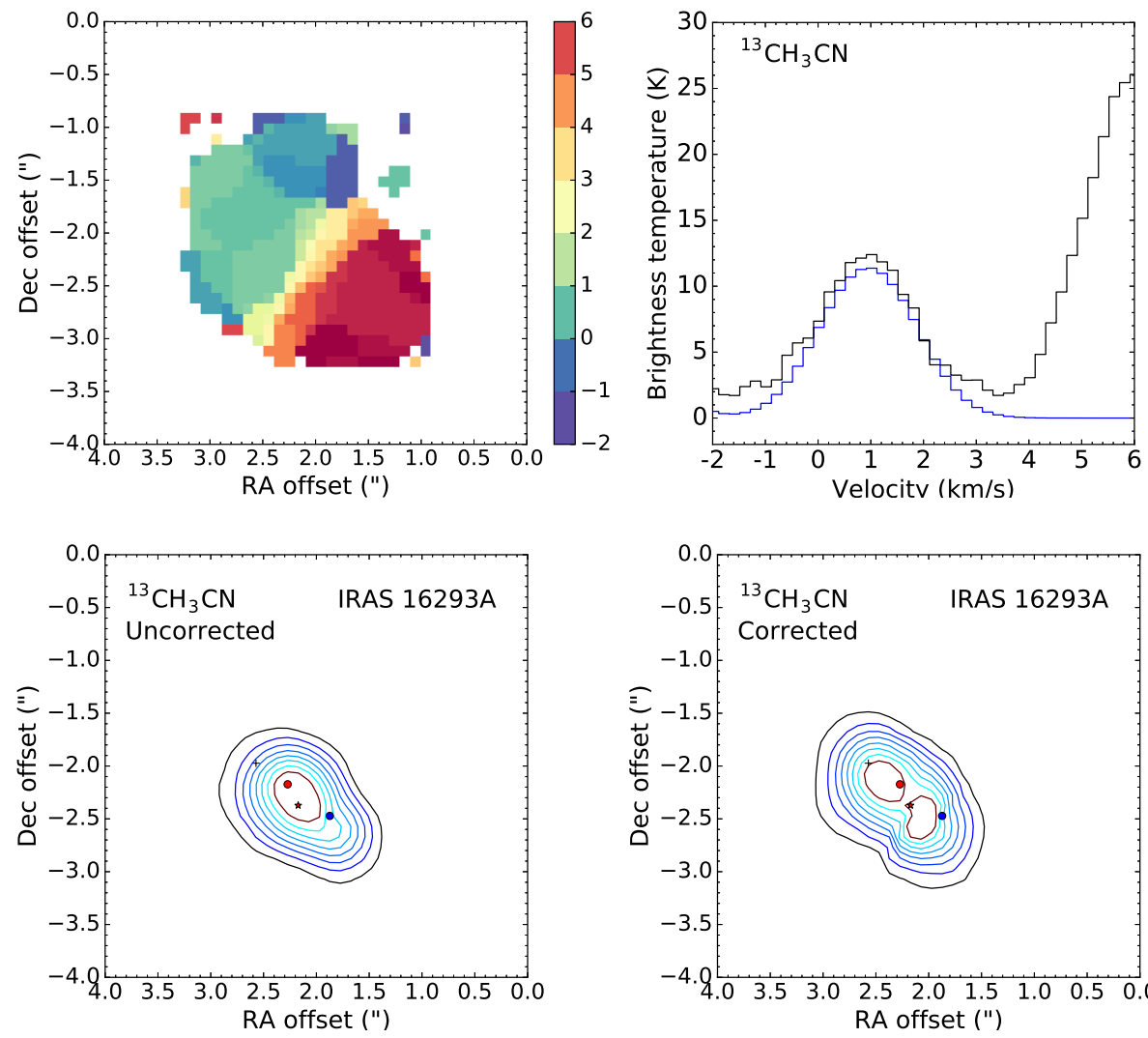

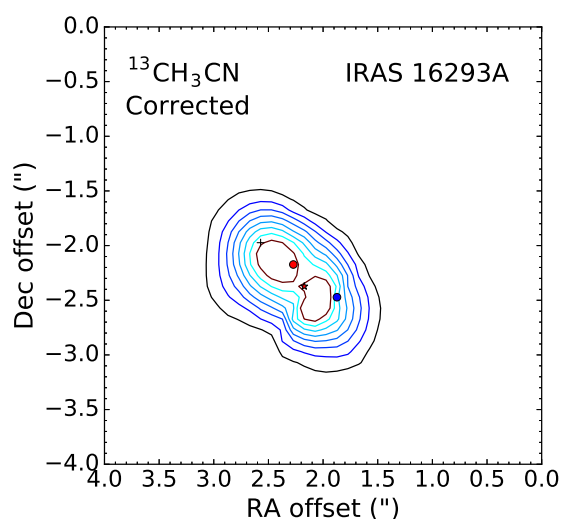

Fig. 4. Top left: velocity map of IRAS 16293A. Top right: spectral lines covered over the velocity gradient of IRAS 16293A. Bottom left: integrated emission map where the emission for the $338.360 \mathrm{GHz}$ line of ${ }^{13} \mathrm{CH}_{3} \mathrm{CN}$ is integrated over channels between 0 and $6 \mathrm{~km} \mathrm{~s}^{-1}$. Bottom right: velocity-corrected integrated emission map of the $338.360 \mathrm{GHz}$ line of ${ }^{13} \mathrm{CH}_{3} \mathrm{CN}$ where only the line profile at each pixel is integrated over. The red star marks the peak continuum position in the PILS dataset of IRAS 16293A and the black cross marks the offset position where the spectra analysed in this work are extracted from. The red and blue circles mark the positions of the two continuum peaks A1 and A2, respectively, found by previous authors, using coordinates that have been corrected by the rate of position angle change with year determined by Pech et al. (2010). that it is the first time a velocity correction has been applied to an integrated emission map.

As an example, the bottom left and right panels of Fig. 4 show two emission maps of the $339.360 \mathrm{GHz}$ line of ${ }^{13} \mathrm{CH}_{3} \mathrm{CN}$. The first map is the emission integrated over $6 \mathrm{~km} \mathrm{~s}^{-1}$. The second emission map has been velocity-corrected, and therefore only includes the emission over the line profile of ${ }^{13} \mathrm{CH}_{3} \mathrm{CN}$. In the first emission map, the range of velocities that is integrated over to cover the emission across the A source leads to contamination by a nearby line, shown in the top-right panel of Fig. 4. Producing a velocity-corrected map means the emission is not contaminated by other lines, and previously unseen structure is resolved as is seen in the second emission map. We recommend using this method for the future analysis of IRAS 16293A molecular emission and other line-rich sources where blending may be an issue.

Figure 5 shows the VINE map for all of the species detected in this work using unblended bright lines. All of the species trace the hot gas surrounding sources A and B, with higher upper energy lines tracing more compact, hotter gas in both sources. Emission around IRAS 16293A has a larger spatial distribution, being on average 1.5 times larger than source B. The larger distribution of methyl cyanide compared to its isotopologues in both sources can be attributed to the difference in line strength between the emission of these molecules.

Emission around IRAS 16293B peaks to the west of the peak continuum position (red star in the figure) due to opacity effects. For most species, emission around IRAS 16293A peaks in two locations either side of the continuum peak position (red star in the figure). A zoomed in version of this double peak structure can be found in Fig. C.1. We do not observe a similar doublepeaked structure in the PILS continuum results in the left panel of Fig. 1 as the emission is optically thick at the observed frequency. Observations at longer wavelengths by Wootten (1989), however, did detect two continuum sources, A1 and A2, associated with IRAS 16293A. Chandler et al. (2005) and Pech et al. (2010) also detected multiple components associated with IRAS $16293 \mathrm{~A}$ and observed a change in their coordinates. The red and blue circles on the figure mark the location of A1 and A2 respectively, using coordinates that have been corrected by the rate of position angle change with year determined by Pech et al. (2010). The small differences observed between the two peaks in the molecular emission found in this work compared to the corrected $\mathrm{A} 1$ and $\mathrm{A} 2$ continuum peaks can be attributed to pointing errors and errors associated with the coordinate correction. Whilst this double-peaked emission could be due to multiple sources in IRAS 16293A, it is more likely to be due to the rotating toroidal structure around source A which is near edgeon. Such emission has been observed before in inclined rotating structures (e.g. Andrews et al. 2009; Matrà et al. 2018). Furthermore, it has been seen in 3D radiative transfer modelling of IRAS 16293 by Jacobsen et al. (2018), where double-peaked emission was found when generating synthetic $\mathrm{CO}$ isotopologue emission maps using a rotating toroid model.

\section{Discussion}

\subsection{Relative abundances}

The results from the abundance determination in each source, as well as the isotopic ratios determined for the ${ }^{12} \mathrm{C} /{ }^{13} \mathrm{C},{ }^{14} \mathrm{~N} /{ }^{15} \mathrm{~N}$ and $\mathrm{D} / \mathrm{H}$ present a picture of two chemically similar sources. In particular, if the relative abundance is determined with respect to methyl cyanide instead of methanol, the differences seen between the molecules are minimal, especially when considering the errors of the observations. The emission maps of both sources suggest a difference in the large-scale emission of nitriles. Previous work by Bisschop et al. (2008) on HNCO 


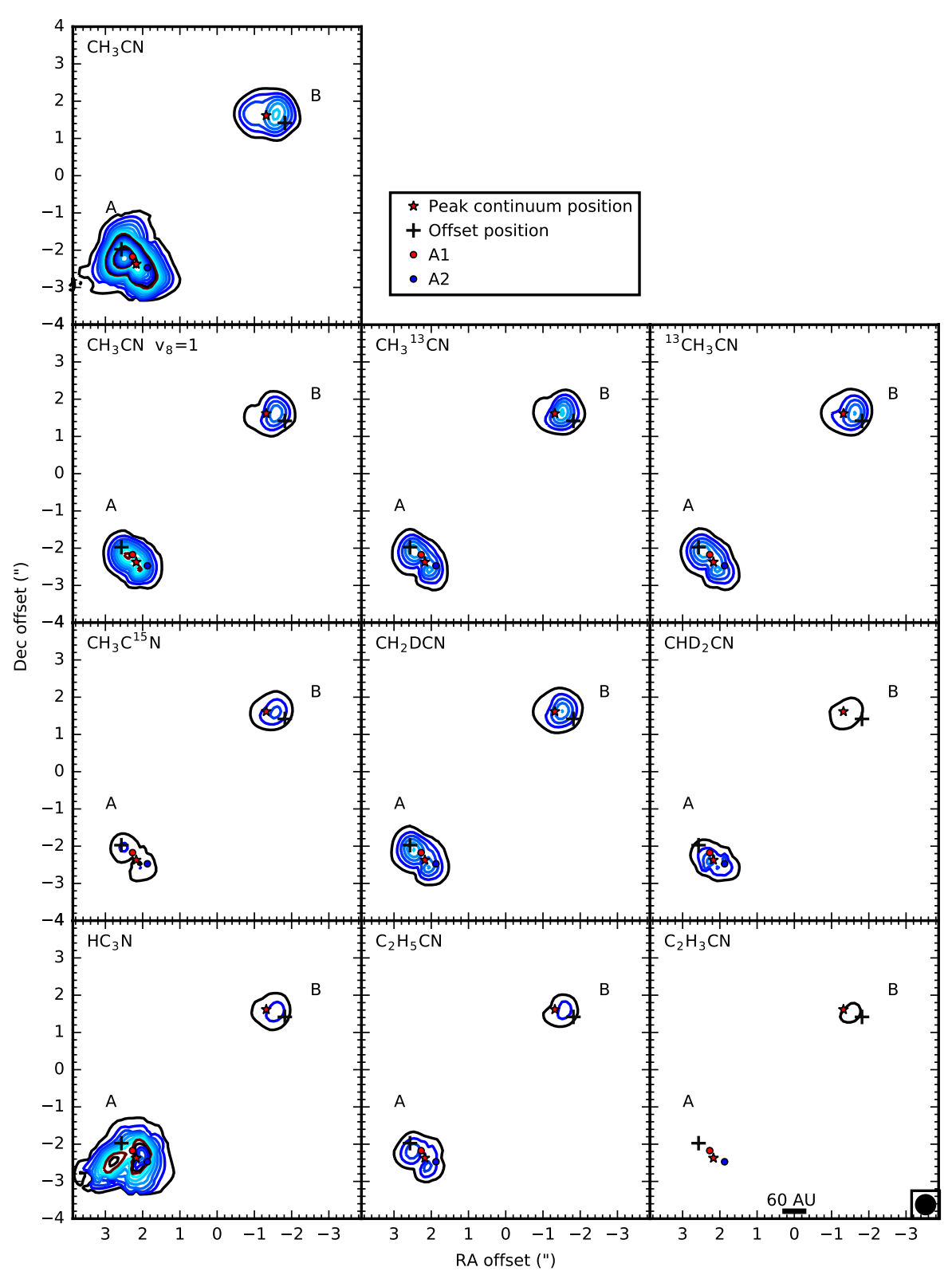

Fig. 5. VINE maps of the $349.346 \mathrm{GHz}$ line of $\mathrm{CH}_{3} \mathrm{CN} v=0$, the $350.168 \mathrm{GHz}$ line of $\mathrm{CH}_{3} \mathrm{CN}$ $v_{8}=1$, the $339.366 \mathrm{GHz}$ line of ${ }^{13} \mathrm{CH}_{3} \mathrm{CN}$, the $349.254 \mathrm{GHz}$ of $\mathrm{CH}_{3}^{13} \mathrm{CN}$, the $338.940 \mathrm{GHz}$ of $\mathrm{CH}_{3} \mathrm{C}^{15} \mathrm{~N}$, the $347.110 \mathrm{GHz}$ of $\mathrm{CH}_{2} \mathrm{DCN}$, the $362.520 \mathrm{GHz}$ of $\mathrm{CHD}_{2} \mathrm{CN}$, the $329.235 \mathrm{GHz}$ of $\mathrm{C}_{2} \mathrm{H}_{5} \mathrm{CN}$, the $341.564 \mathrm{GHz}$ of $\mathrm{C}_{2} \mathrm{H}_{3} \mathrm{CN}$ and the $336.520 \mathrm{GHz}$ of $\mathrm{HC}_{3} \mathrm{~N}$. The axes show the position offset from the phase centre of the observations. Contour levels start at $80 \mathrm{mJy} \mathrm{km} \mathrm{s}^{-1}$ and increase in steps of $11 \mathrm{mJy} \mathrm{km} \mathrm{s}^{-1}$. The red stars mark the peak continuum position in the PILS dataset of IRAS 16293A and IRAS 16293B. The black crosses mark the offset positions where the spectra analysed in this work are extracted from. The red and blue circles mark the positions of the two continuum peaks A1 and A2, respectively, found by previous authors using coordinates that have been corrected by the rate of position angle change with year determined by Pech et al. (2010). and methyl cyanide emission indicated that nitrogen-bearing species are more abundant relative to methanol (derived from the $\mathrm{CH}_{3}{ }^{18} \mathrm{OH}$ column density) towards $\mathrm{B}$ compared with $\mathrm{A}$, with only 10-20\% arising from source B. Whilst we do not find such a stark difference in abundance, likely due to unaccounted-for optical depth, beam dilution effects in the previous estimate, and a larger beam, we do find that the bulk of nitrile emission peaks towards the A source, showing a more extended spatial distribution which is particularly evident in $\mathrm{HC}_{3} \mathrm{~N}$ and methyl cyanide, especially when compared to the spatial extent of $\mathrm{CH}_{3}{ }^{18} \mathrm{OH}$. Such comparisons between sources are also highly dependent on which species the abundance is calculated relative to, as we show in Sect. 3.2, where abundances computed relative to methanol show a greater difference between $\mathrm{A}$ and $\mathrm{B}$.

The significant difference that is seen between the sources is the relative abundance of vinyl cyanide, which is not detected towards IRAS 16293A but is detected towards IRAS 16293B. A factor of nine difference in abundance between the sources indicates a significant difference in the chemistry or physical conditions for this species. This difference in abundance is also seen in the emission maps presented in Sect. 3.4, with no vinyl cyanide emission at any position around IRAS 16293A. Some authors have previously suggested that vinyl cyanide could be used as an evolutionary indicator in hot cores (Caselli et al. 1993; Fontani et al. 2007), with higher abundances relative to ethyl cyanide indicating a more evolved object. Differences in the ratio of vinyl cyanide to ethyl cyanide can be expected at different stages of evolution as their formation pathways are closely linked. Vinyl cyanide forms early in low-mass star formation on dust grains from the hydrogenation of $\mathrm{HC}_{3} \mathrm{~N}$, however, it is rapidly hydrogenated further to ethyl cyanide. Garrod et al. (2017) find that the vinyl cyanide abundance only becomes significant later during the warm-up phase, when it is formed as a result of the destruction of ethyl cyanide through protonation and subsequent dissociative electronic recombination, producing vinyl cyanide as one of several possible branches. These models suggest that differences in vinyl cyanide abundance between sources either indicate a difference in evolution or at least a difference in the timescale of the warm-up phase. In IRAS $16293 \mathrm{~B}$, the ethyl cyanide to vinyl cyanide ratio is five, while in IRAS 16293A it is $>53$, which, if such a ratio can be used as an evolutionary indicator, would suggest that 
the B source is more evolved, or at least has a longer warm-up timescale, having had more time for vinyl cyanide to be formed in the gas.

The outflow distribution in IRAS 16293, however, paints a different picture of the evolution of these two sources. At least two major outflows have been observed from IRAS 16293A, a northwest outflow (Kristensen et al. 2013; Girart et al. 2014) and an east-west bipolar outflow (Yeh et al. 2008). IRAS 16293B, however, shows no clear signs of outflows, which suggests it is the younger, more embedded source. These conflicting indications of evolution make it difficult to determine the exact evolution of either source. There is, however, another scenario which could lead to both observed differences, if both sources have the same physical age and mass but the A source has higher accretion rate. This would lead to outflows from source A and warm-up timescales so short that vinyl cyanide is not efficiently formed. Such differences would lead to a higher luminosity for the A source compared to the B source, which is supported by recent $3 \mathrm{D}$ modelling of the envelope, disks, and dust filament by Jacobsen et al. (2018).

\subsection{Isotopic ratios}

The isotopic ratios presented in Sect. 3.3 are not able to put strict constraints on the formation paths of methyl cyanide. They do, however, tell us something about the enrichment of methyl cyanide isotopologues in IRAS 16293. In particular, the higher $\mathrm{D} / \mathrm{H}$ ratio when determined from the doubly deuterated form of methyl cyanide, compared to the singly deuterated form, suggests an enrichment of deuterium in methyl cyanide. A similar enrichment in the $\mathrm{D} / \mathrm{H}$ ratio is also found in formaldehyde (Persson et al. 2018) and methyl formate (Manigand et al. 2018), implying a mechanism for the enrichment of deuterated species. Oba et al. (2016a,b) found H-D substitution could occur on the methyl group of ethanol and dimethyl ether on ice grain surfaces. This could be occurring for methyl cyanide. This process seems more enhanced for IRAS $16293 \mathrm{~B}$ with $\mathrm{D} / \mathrm{H}$ ratios derived from the doubly deuterated form even more enhanced compared to the singly deuterated form. This could imply a longer period of $\mathrm{H}-\mathrm{D}$ substitution in IRAS 16293B than in IRAS 16293A.

\subsection{Comparison to other sources}

To put the results of this analysis into a wider context, it is useful to compare them to similar studies of complex organic molecules in other objects. The EMoCA survey of complex organic molecules with ALMA in Sagittarius B2(N2) (henceforth Sgr B2(N2)) provides the data to make such a comparison. Sgr B2(N2) is one of the most line-rich sources and therefore one of the most studied sources in the galaxy. It is also the only other source where a detailed study of nitrile species has been performed with high-resolution observations. In the top panel of Fig. 3, the abundance of nitriles with respect to methyl cyanide determined in Sgr B2(N2) by Belloche et al. (2016) is plotted as well as the abundances for IRAS 16293A and IRAS 16293B. Similar abundances are found for $\mathrm{CH}_{3} \mathrm{C}^{15} \mathrm{~N}$ between the three sources whereas for the other species, large differences are seen. Both forms of ${ }^{13} \mathrm{C}$ methyl cyanide are approximately three times more abundant in Sgr B2(N2) than in IRAS 16293. It is interesting that there are no abundance differences for different functional groups in any of the three sources. The deuteration level also seems to be less in Sgr B2(N2) with a lower abundance of $\mathrm{CH}_{2} \mathrm{DCN}$ and no detection of doubly deuterated methyl cyanide.
The abundance of ethyl cyanide, vinyl cyanide, and cyanoacetylene are also significantly more abundant in Sgr B2(N2) compared to IRAS 16293.

\section{Summary and conclusions}

This work presents a detailed study of nitriles in IRAS 16293. Using ALMA observations from the PILS survey and LTE spectral modelling, the excitation temperatures and column densities towards both protostellar sources IRAS 16293A and IRAS $16293 \mathrm{~B}$ are determined. The main findings are as follows.

Methyl cyanide is detected in both the $v=0$ and $v_{8}=1$ states, as well as five of its isotopologues, including $\mathrm{CHD}_{2} \mathrm{CN}$ for the first time in the ISM. Ethyl cyanide, vinyl cyanide, and $\mathrm{HC}_{3} \mathrm{~N}$ are also detected.

All species have excitation temperatures in the range $100-160 \mathrm{~K}$, based on LTE spectral models of their emission. We have also used LTE spectral models to determine the relative abundance of nitriles in IRAS 16293A and IRAS 16293B, with respect to methanol and methyl cyanide. Most nitriles peak in bulk emission towards IRAS 16293A; however, the differences in abundance between A and B on small scales are not significant, particularly when determined with respect to methyl cyanide. The one exception to this trend is vinyl cyanide which is detected in IRAS 16293B but not in IRAS 16293A. Vinyl cyanide is found to be at least nine times more abundant towards the B source. The large difference in abundance between the sources for vinyl cyanide is due to physical or chemical differences.

The formation paths of ethyl cyanide and vinyl cyanide are closely linked in the models of Garrod et al. (2017), with their relative abundance being highly dependent on evolutionary stage. In such a scenario, the differences observed in IRAS 16293 would imply the B source is more evolved, having had time for vinyl cyanide to form in the gas, or warm-up timescales are so short in IRAS 16293A that vinyl cyanide is not efficiently formed. If both sources have the same physical age and mass, such differences could also be seen if IRAS 16293A has a higher accretion rate.

Comparison of these results to similar studies in Sgr B2(N2) highlight how despite the difference between low-mass sources and Galactic Centre hot cores, differing functional group does not seem to impact the abundance of ${ }^{13} \mathrm{C}$ isotopologues.

The isotopic ratios determined in this work are similar for both IRAS $16293 \mathrm{~A}$ and IRAS $16293 \mathrm{~B}$. The ${ }^{12} \mathrm{C} /{ }^{13} \mathrm{C}$ ratio determined for methyl cyanide are $80 \pm 19\left({ }^{13} \mathrm{CH}_{3} \mathrm{CN} / \mathrm{CH}_{3} \mathrm{CN}\right)$ and $67 \pm 14\left(\mathrm{CH}_{3}^{13} \mathrm{CN} / \mathrm{CH}_{3} \mathrm{CN}\right)$ in IRAS $16293 \mathrm{~A}$ and $67 \pm 17$ $\left({ }^{13} \mathrm{CH}_{3} \mathrm{CN} / \mathrm{CH}_{3} \mathrm{CN}\right)$ and $80 \pm 20\left(\mathrm{CH}_{3}^{13} \mathrm{CN} / \mathrm{CH}_{3} \mathrm{CN}\right)$ in IRAS $16293 \mathrm{~B}$. These values are within the error range of the ISM value of $68 \pm 15$ (Milam et al. 2005). The D/H values $(1.2 \pm 0.3-$ $1.5 \pm 0.3 \%$ ) for both sources when using singly deuterated column densities are consistent with those found for methanol, ketene, formic acid, formaldehyde, formamide and isocyanic acid $(\sim 2 \%)$ in this object by previous authors (Jørgensen et al. 2017; Coutens et al. 2016) which also have a ${ }^{12} \mathrm{C} /{ }^{13} \mathrm{C}$ ratio similar to the ISM. This contrasts with ethanol, methyl formate, and glycolaldehyde which exhibit lower ${ }^{12} \mathrm{C} /{ }^{13} \mathrm{C}(25-41 \%)$ ratios and larger $\mathrm{D} / \mathrm{H}$ ratios $(5-6 \%)$. The $\mathrm{D} / \mathrm{H}$ values derived from doubly deuterated column densities are a factor of two higher in IRAS 16293A and more than a factor of three higher in IRAS 16293B. A similar enhancement in the $\mathrm{D} / \mathrm{H}$ ratio is also found in formaldehyde (Persson et al. 2018) and methyl formate (Manigand et al. 2018), suggesting that a mechanism of enrichment occurs, such as H-D substitution. 
In this work we explore the spatial extent of nitrile organics. We present a new technique to explore the spatial structures in sources with high molecular line density and large velocity gradients - VINE maps. Using this novel technique, we resolve two peaks in the molecular emission around source A for the first time, as has been found previously in continuum observations (see Chandler et al. 2005; Pech et al. 2010; Wootten 1989). This double-peak structure is likely a consequence of the rotating toroid structure around source $\mathrm{A}$, and not an indication of multiple sources in source A.

Whilst most abundances presented in this work are similar between IRAS 16293A and IRAS 16293B, the abundances of vinyl cyanide indicate possible differences in the evolution of these two sources; the reason for their chemical differentiation is far from clear, and further chemical models are needed that fully reproduce their relative abundances. Further higherangular-resolution observations are also needed to understand the double-peaked emission observed in the A source. The number of nitriles and their isotopologues detected in IRAS 16293 highlights the rich chemistry which is observed in this object. Observing the emission of many different species in the same family of molecules can build up a detailed picture of the chemical similarities and differences between IRAS 16293A and IRAS 16293B, as well as probe the physical structures observed in both sources.

Acknowledgements. The authors would like to thank the referee for their helpful comments on the manuscript. The authors would like to acknowledge the European Union whose support has been essential to this research. In particular a European Research Council (ERC) grant, under the Horizon 2020 research and innovation programme (grant agreement No. 646908) through ERC Consolidator Grant "S4F" to J.K.J. The group of EvD acknowledges ERC Advanced Grant "CHEMPLAN" (grant agreement No 291141). AC postdoctora grant is funded by the ERC Starting Grant 3DICE (grant agreement 336474). MVP postdoctoral position is funded by the ERC consolidator grant 614264 . S.F.W. acknowledges financial support from a CSH fellowship. Research at the Centre for Star and Planet Formation is funded by the Danish National Research Foundation. This paper makes use of the following ALMA data: ADS/JAO.ALMA\#2013.1.00278.S. ALMA is a partnership of ESO (representing its member states), NSF (USA) and NINS (Japan), together with NRC (Canada) and NSC and ASIAA (Taiwan), in cooperation with the Republic of Chile. The Joint ALMA Observatory is operated by ESO, AUI/NRAO and NAOJ.

\section{References}

Andrews, S. M., Wilner, D. J., Hughes, A. M., Qi, C., \& Dullemond, C. P. 2009 ApJ, 700, 1502

Banerjee, A., Ganguly, G., Tripathi, R., Nair, N. N., \& Paul, A. 2014, Chem. Eur. J., 20, 6348

Belloche, A., Müller, H. S. P., Garrod, R. T., \& Menten, K. M. 2016, A\&A, 587, A91

Beltrán, M. T., Cesaroni, R., Neri, R., et al. 2005, A\&A, 435, 901

Bisschop, S. E., Jørgensen, J. K., Bourke, T. L., Bottinelli, S., \& Van Dishoeck, E. F. 2008, A\&A, 488, 11

Bottinelli, S., Ceccarelli, C., Neri, R., et al. 2004, ApJ, 617, L69

Brauer, C. S., Pearson, J. C., Drouin, B. J., \& Yu, S. 2009, ApJS, 184, 133

Caselli, P., Hasegawa, T. I., \& Herbst, E. 1993, ApJ, 408, 548

Caux, E., Kahane, C., Castets, A., et al. 2011, A\&A, 532, A23

Ceccarelli, C., Castets, A., Caux, E., et al. 2000, A\&A, 355, 1129

Cesaroni, R., Sánchez-Monge, Á., Beltrán, M. T., et al. 2017, A\&A, 602, A59

Chandler, C. J., Brogan, C. L., Shirley, Y. L., \& Loinard, L. 2005, ApJ, 632, 371

Coutens, A., Jørgensen, J. K., van der Wiel, M. H. D., et al. 2016, A\&A, 590, L6

Coutens, A., Willis, E. R., Garrod, R. T., et al. 2018, A\&A, 612, A107
Demaison, J., Cosleou, J., Bocquet, R., \& Lesarri, A. G. 1994, J. Mol. Spectr., 167,400

Favre, C., Pagani, L., Goldsmith, P. F., et al. 2017, A\&A, 604, L2

Fontani, F., Pascucci, I., Caselli, P., et al. 2007, A\&A, 652, 639

Fukuyama, Y., Odashima, H., Takagi, K., \& Tsunekawa, S. 1996, ApJS, 104, 329

Garrod, R. T., Belloche, A., Müller, H. S. P., \& Menten, K. M. 2017, A\&A, 601, A48

Girart, J. M., Estalella, R., Palau, A., Torrelles, J. M., \& Rao, R. 2014, ApJ, 780, L11

Halonen, L., \& Mills, I. M. 1978, J. Mol. Spectr., 73, 494

Heise, H. M., Winther, F., \& Lutz, H. 1981, J. Mol. Spectr., 90, 531

Isokoski, K., Bottinelli, S., \& van Dishoeck, E. F. 2013, A\&A, 554, A100

Jaber, A. A., Ceccarelli, C., Kahane, C., et al. 2017, A\&A, 587, A40

Jacobsen, S. K., Jørgensen, J. K., van der Wiel, M. H. D., et al. 2018, A\&A, 612, A72

Jiménez-Serra, I., Vasyunin, A. I., Caselli, P., et al. 2016, ApJ, 830, L6

Jørgensen, J. K., Bourke, T. L., Luong, Q. N., \& Takakuwa, S. 2011, A\&A, 534, A 100

Jørgensen, J. K., van der Wiel, M. H. D., Coutens, A., et al. 2016, A\&A, 595, A 117

Jørgensen, J. K., Müller, H. S. P., Calcutt, H., et al. 2017, A\&A, submitted Khlifi, M., Nollet, M., Paillous, P., et al. 1999, J. Mol. Spectr., 194, 206 Kristensen, L. E., Klaassen, P. D., Mottram, J. C., Schmalzl, M., \& Hogerheijde, M. R. 2013, A\&A, 549, L6

Kuan, Y.-J., Huang, H.-C., Charnley, S. B., et al. 2004, ApJ, 616, 27

Le Guennec, M., Wlodarczak, G., Burie, J., \& Demaison, J. 1992, J. Mol. Spectr. 154,305

Ligterink, N. F. W., Coutens, A., Kofman, V., et al. 2017, MNRAS, 469, 2219

Loinard, L., Torres, R. M., Mioduszewski, A. J., \& Rodríguez, L. F. 2008, ApJ, 675, L29

Lykke, J. M., Coutens, A., Jørgensen, J. K., et al. 2017, A\&A, 597, A53

Mallinson, P. D., \& Fayt, A. 1976, Mol. Phys., 32, 473

Manigand, S., Calcutt, H., Jørgensen, J. K., et al. 2018, A\&A, submitted

Marino, S., Matrà, L., Stark, C., et al. 2016, MNRAS, 460, 2933

Matrà, L., Panić, O., Wyatt, M. C., \& Dent, W. R. F. 2015, MNRAS, 447, 3936

Matrà, L., Wilner, D. J., Öberg, K. I., et al. 2018, ApJ, 853, 147

Milam, S. N., Savage, C., Brewster, M. A., \& Ziurys, L. M. 2005, ApJ, 634, 1126

Müller, H. S. P., Belloche, A., Menten, K. M., Comito, C., \& Schilke, P. 2008,

J. Mol. Spectr., 251, 319

Müller, H. S. P., Drouin, B. J., \& Pearson, J. C. 2009, A\&A, 506, 1487

Müller, H. S. P., Brown, L. R., Drouin, B. J., et al. 2015, J. Mol. Spectr., 312, 22

Mumma, M. J., \& Charnley, S. B. 2011, ARA\&A, 49, 471

Nguyen, L., Walters, A., Margulès, L., et al. 2013, A\&A, 553, A84

Oba, Y., Osaka, K., Chigai, T., Kouchi, A., \& Watanabe, N. 2016a, MNRAS, 462, 689

Oba, Y, Takano, Y, Watanabe, N., \& Kouchi, A. 2016b, ApJ, 827, L18

Öberg, K. I., Guzmán, V. V., Furuya, K., et al. 2015, Nature, 520, 198

Pearson, J. C., \& Müller, H. S. P. 1996, ApJ, 471, 1067

Pearson, J. C., Sastry, K. V. L. N., Herbst, E., \& De Lucia, F. C. 1994, ApJS, 93, 589

Pech, G., Loinard, L., Chandler, C. J., et al. 2010, ApJ, 712, 1403

Persson, M. V., Jørgensen, J. K., Müller, H. S. P., et al. 2018, A\&A, 610, A54

Pineda, J. E., Maury, A. J., Fuller, G. A., et al. 2012, A\&A, 544, L7

Powner, M. W., Gerland, B., \& Sutherland, J. D. 2009, Nature, 459, 239

Schöier, F. L., Jørgensen, J. K., van Dishoeck, E. F., \& Blake, G. A. 2002, A\&A, 390, 1001

Snyder, L. E., Lovas, F. J., Hollis, J. M., et al. 2005, ApJ, 619, 914

Stevenson, J., Lunine, J., \& Clancy, P. 2015, Sci. Adv., 1, 1400067

Thorwirth, S., Müller, H. S. P., \& Winnewisser, G. 2000, J. Mol. Spectr., 204, 133

van Dishoeck, E. F., Blake, G. A., Jansen, D. J., \& Groesbeck, T. D. 1995, ApJ, 447, 760

Walsh, C., Loomis, R. A., Öberg, K. I., et al. 2016, ApJ, 823, L10

Wampfler, S. F., Jørgensen, J. K., Bizzarro, M., \& Bisschop, S. E. 2014, A\&A, 572,16

Wilson, T. L., \& Rood, R. 1994, ARA\&A, 32, 191

Wootten, A. 1989, ApJ, 337, 858

Yamada, K. M. T., Moravec, A., \& Winnewisser, G. 1995, Z. Naturforsch. A, 50, 1179

Yeh, S. C. C., Hirano, N., Bourke, T. L., et al. 2008, ApJ, 675, 454

Yen, H.-W., Koch, P. M., Liu, H. B., et al. 2016, ApJ, 832, 204 


\section{Appendix A: Spectra}

Spectra of the nine brightest lines of $\mathrm{CH}_{3} \mathrm{CN} v_{8}=1,{ }^{13} \mathrm{CH}_{3} \mathrm{CN}, \mathrm{CH}_{3}{ }^{13} \mathrm{CN}, \mathrm{CH}_{3} \mathrm{C}^{15} \mathrm{~N}, \mathrm{CH}_{2} \mathrm{DCN}, \mathrm{CHD}_{2} \mathrm{CN}_{2} \mathrm{C}_{2} \mathrm{H}_{3} \mathrm{CN}, \mathrm{C}_{2} \mathrm{H}_{5} \mathrm{CN}$, and $\mathrm{HC}_{3} \mathrm{~N}$.
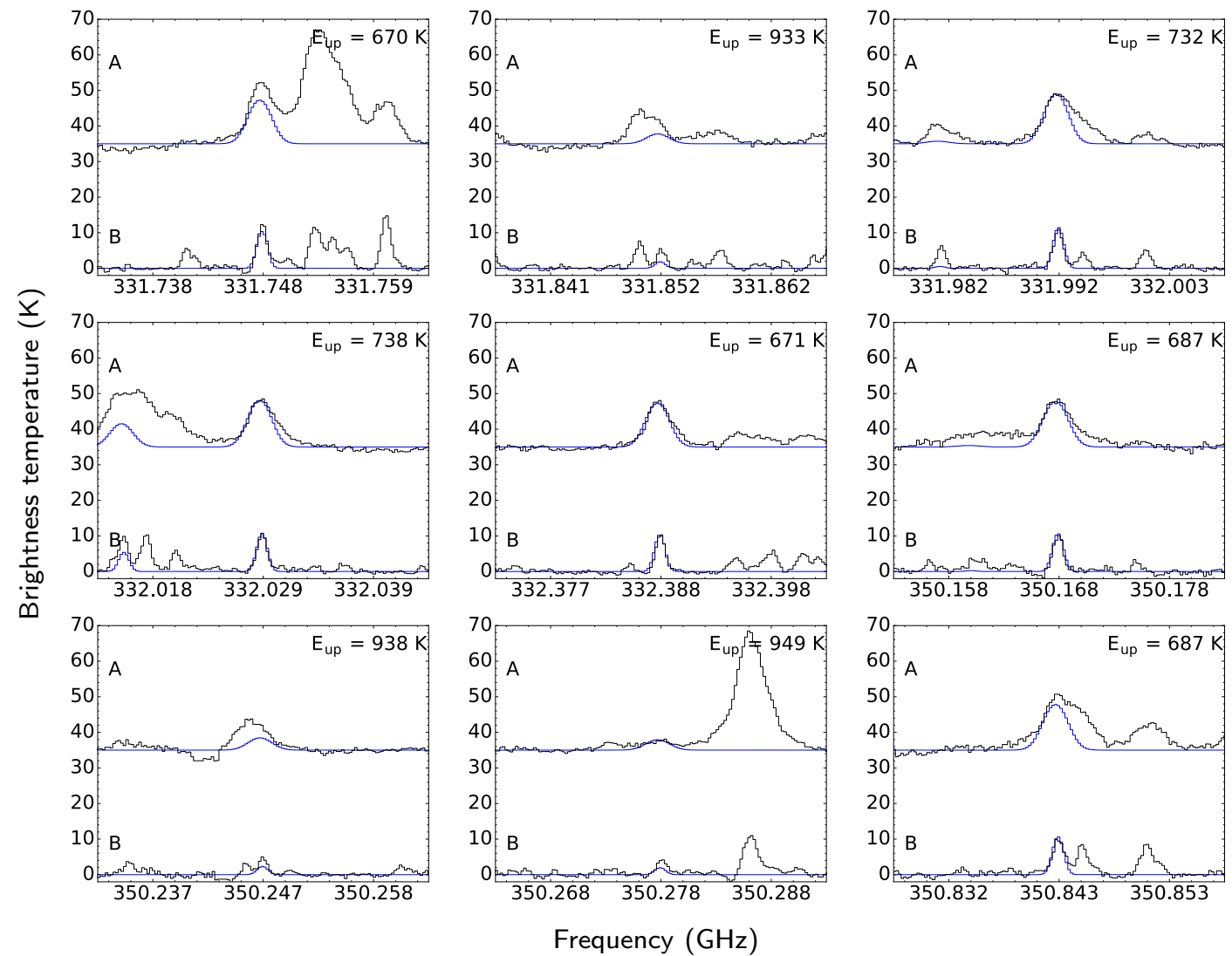

Fig. A.1. Nine brightest lines of $\mathrm{CH}_{3} \mathrm{CN} v_{8}=1$ detected in IRAS 16293A and IRAS 16293B overlaid with the LTE spectral model of the emission in each source. Source A is offset by $35 \mathrm{~K}$ on the $y$-axis. 

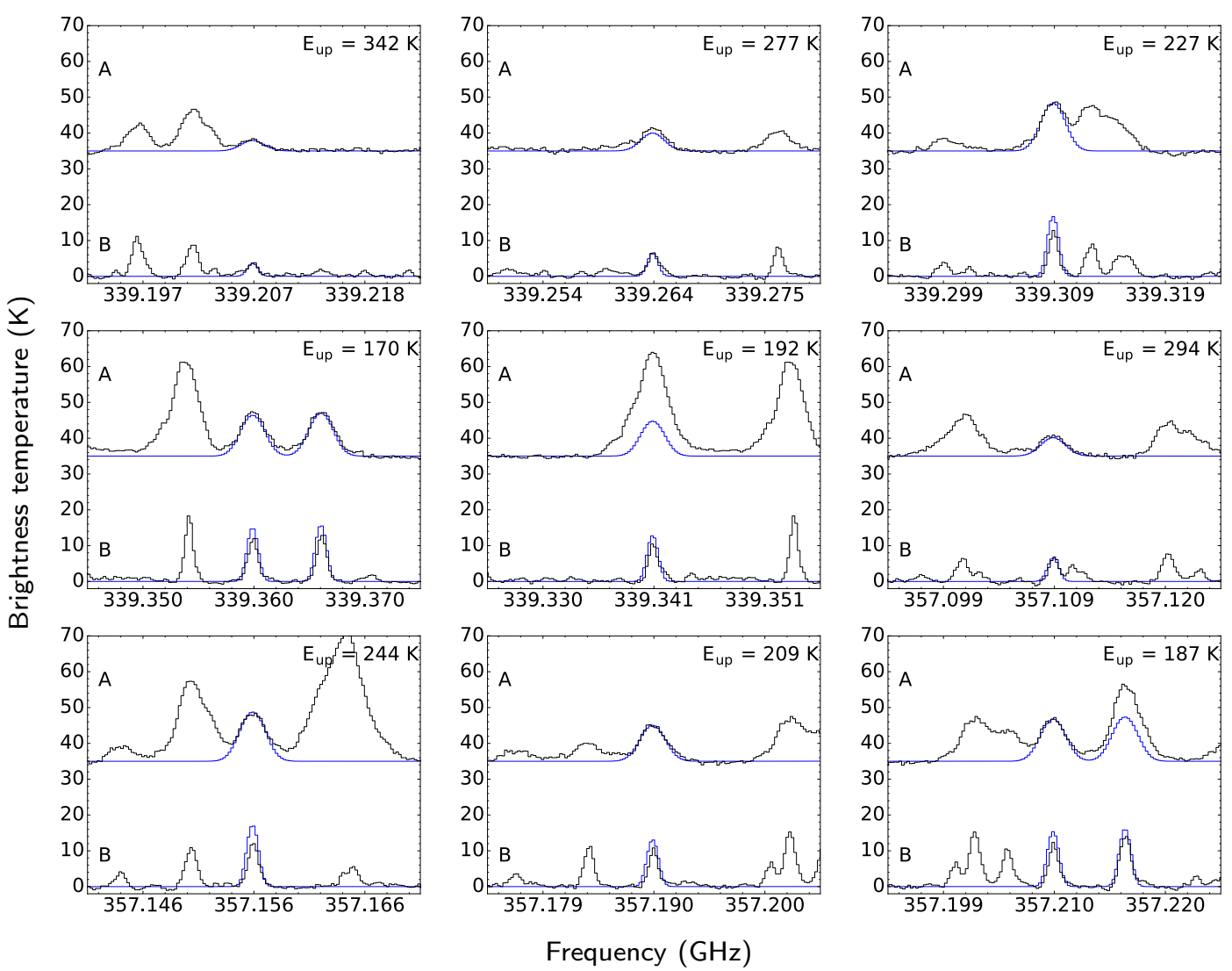

Fig. A.2. Nine brightest lines of ${ }^{13} \mathrm{CH}_{3} \mathrm{CN}$ detected in IRAS 16293A and IRAS 16293B overlaid with an LTE spectral model of the emission in each source. Source A is offset by $35 \mathrm{~K}$ on the $y$-axis.
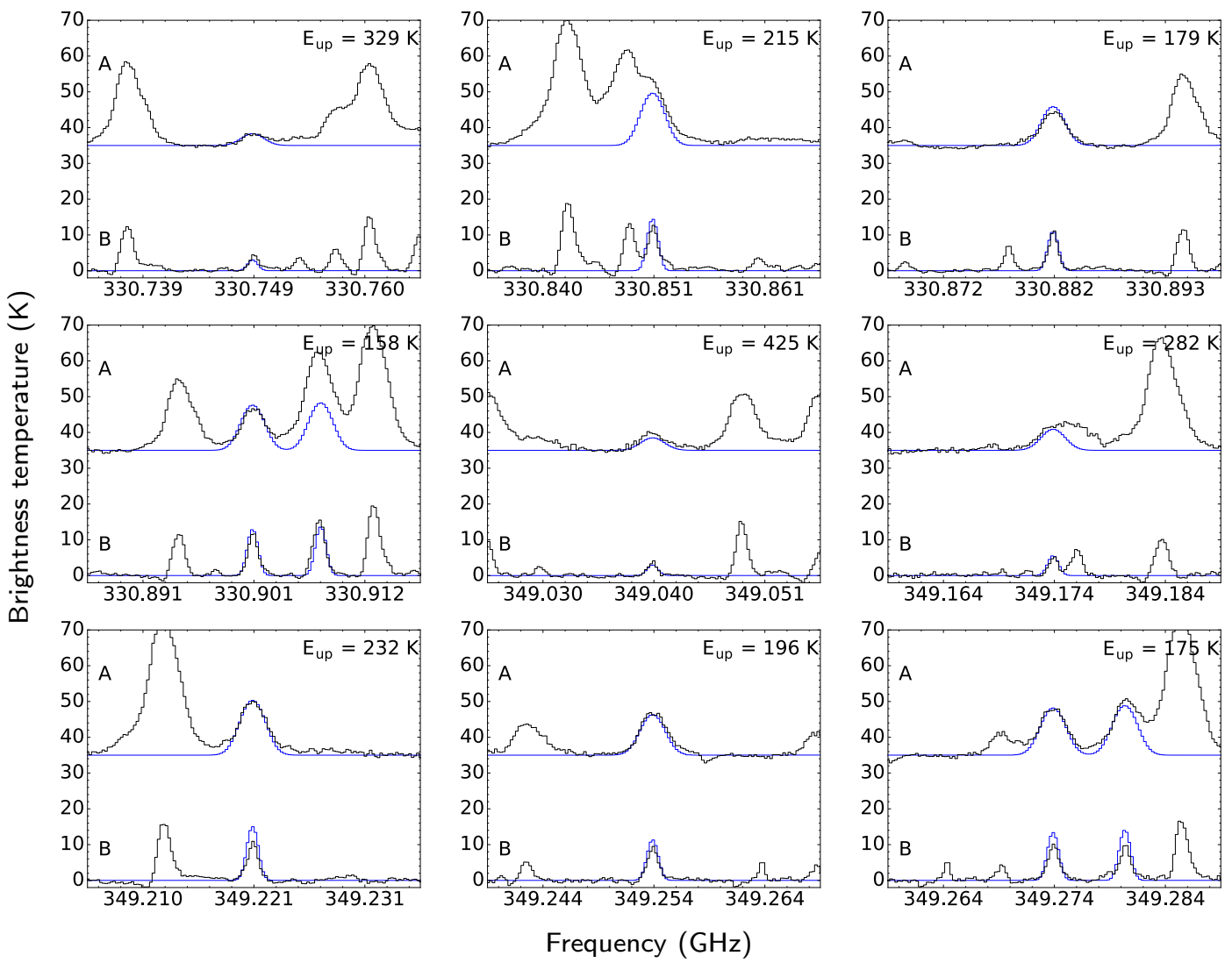

Fig. A.3. Nine brightest lines of $\mathrm{CH}_{3}{ }^{13} \mathrm{CN}$ detected in IRAS 16293A and IRAS 16293B overlaid with an LTE spectral model of the emission in each source. Source A is offset by $35 \mathrm{~K}$ on the $y$-axis. 
H. Calcutt et al.: Complex nitriles towards IRAS 16293-2422
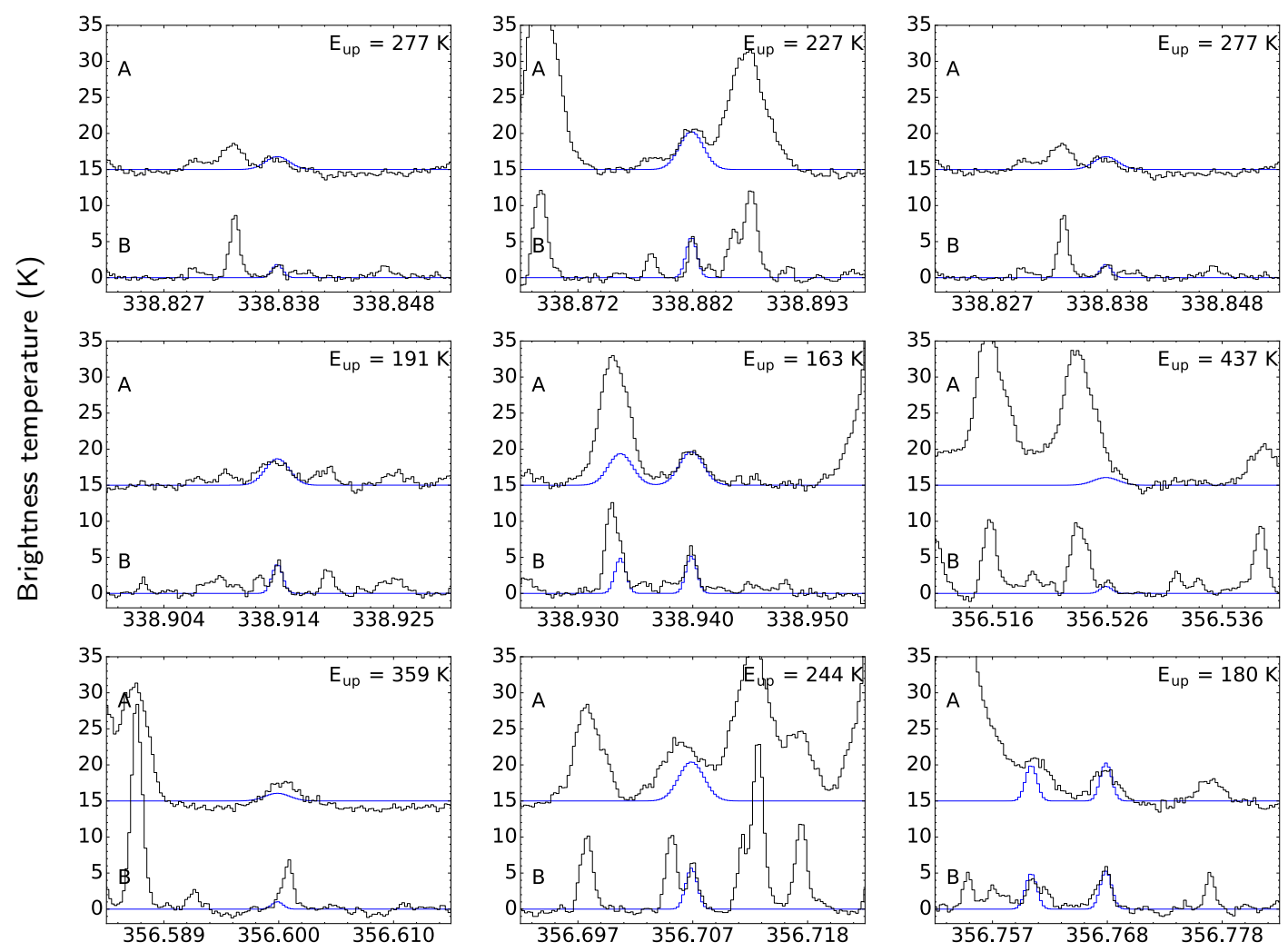

Frequency $(\mathrm{GHz})$

Fig. A.4. Nine brightest lines of $\mathrm{CH}_{3} \mathrm{C}^{15} \mathrm{~N}$ detected in IRAS 16293A and IRAS 16293B overlaid with an LTE spectral model of the emission in each source. Source A is offset by $35 \mathrm{~K}$ on the $y$-axis.
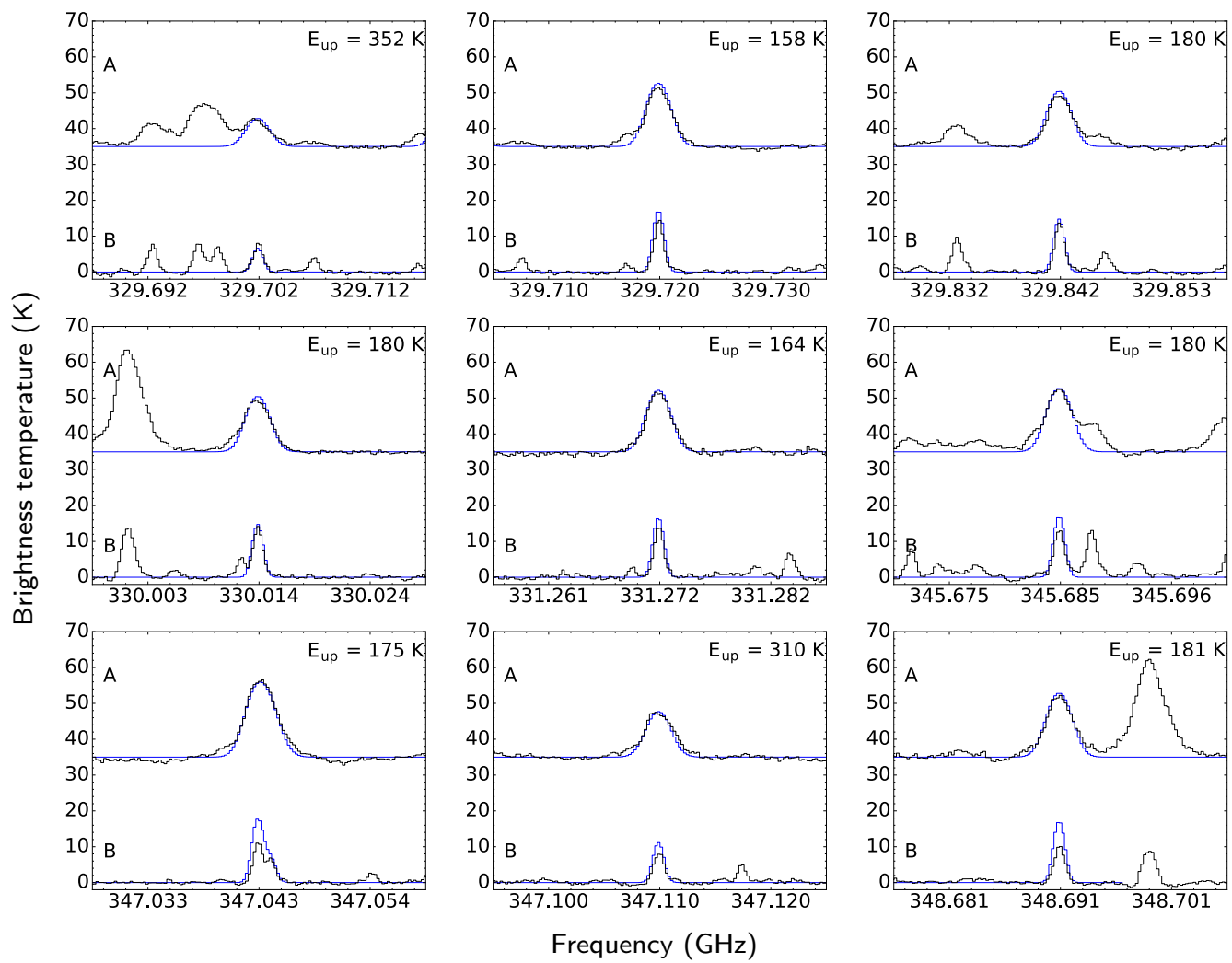

Fig. A.5. Nine brightest lines of $\mathrm{CH}_{2} \mathrm{DCN}$ detected in IRAS 16293A and IRAS 16293B overlaid with an LTE spectral model of the emission in each source. Source A is offset by $35 \mathrm{~K}$ on the $y$-axis. 

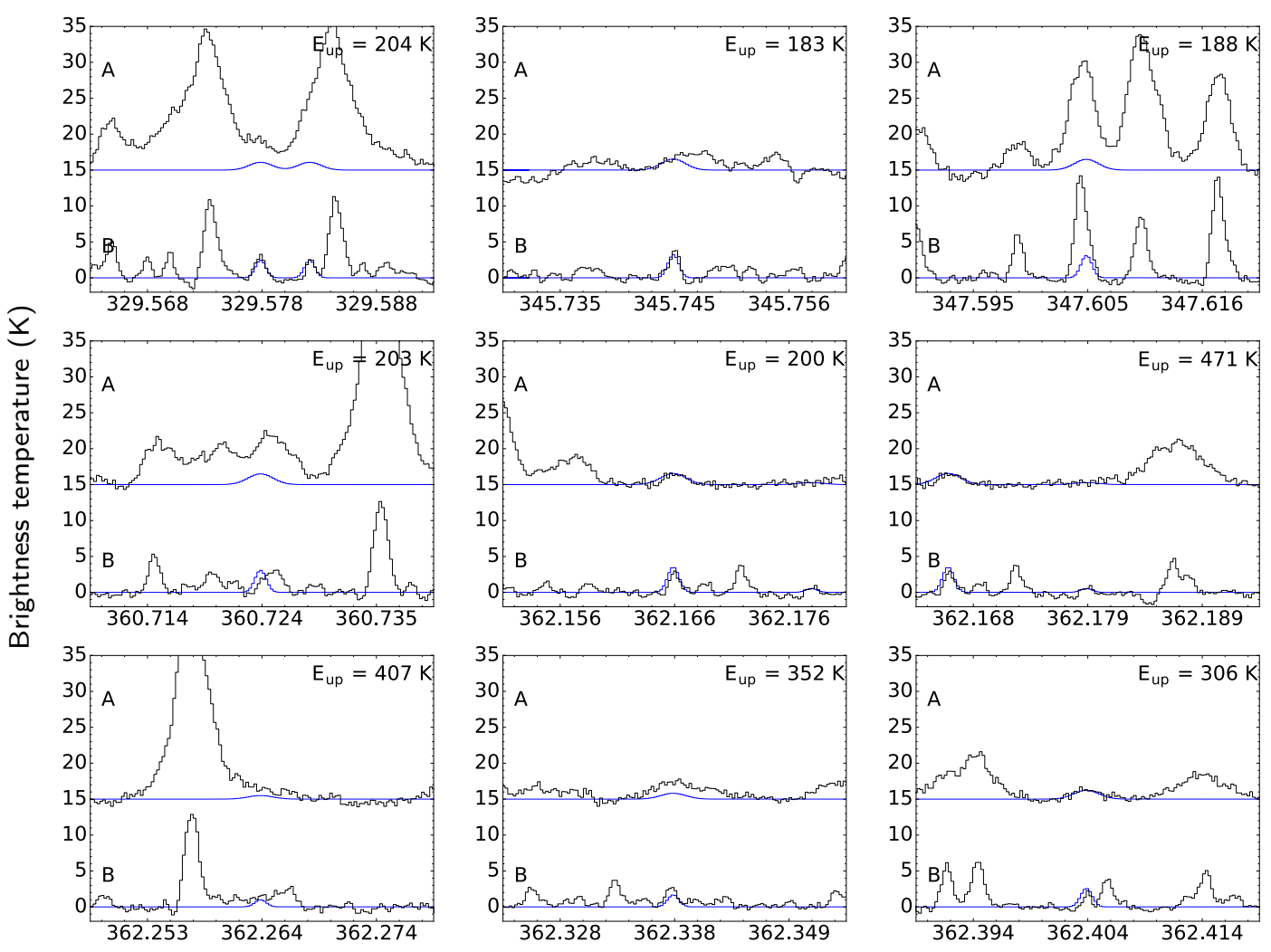

Frequency $(\mathrm{GHz})$

Fig. A.6. Nine brightest lines of $\mathrm{CHD}_{2} \mathrm{CN}$ detected in IRAS 16293A and IRAS 16293B overlaid with an LTE spectral model of the emission in each source. Source A is offset by $35 \mathrm{~K}$ on the $y$-axis.
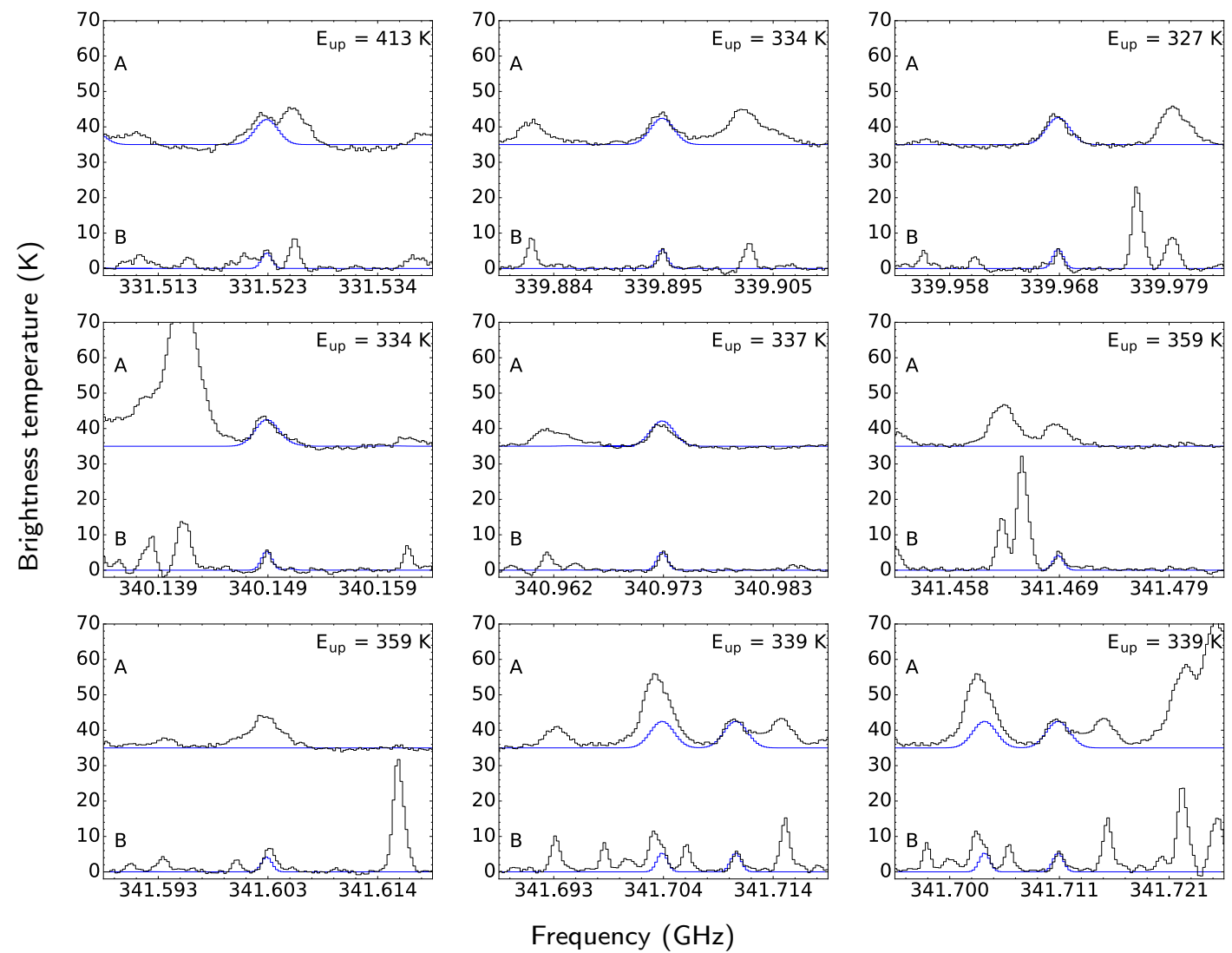

Fig. A.7. Nine brightest lines of $\mathrm{C}_{2} \mathrm{H}_{5} \mathrm{CN}$ detected in IRAS 16293A and IRAS 16293B overlaid with an LTE spectral model of the emission in each source. Source A is offset by $35 \mathrm{~K}$ on the $y$-axis. 
H. Calcutt et al.: Complex nitriles towards IRAS 16293-2422
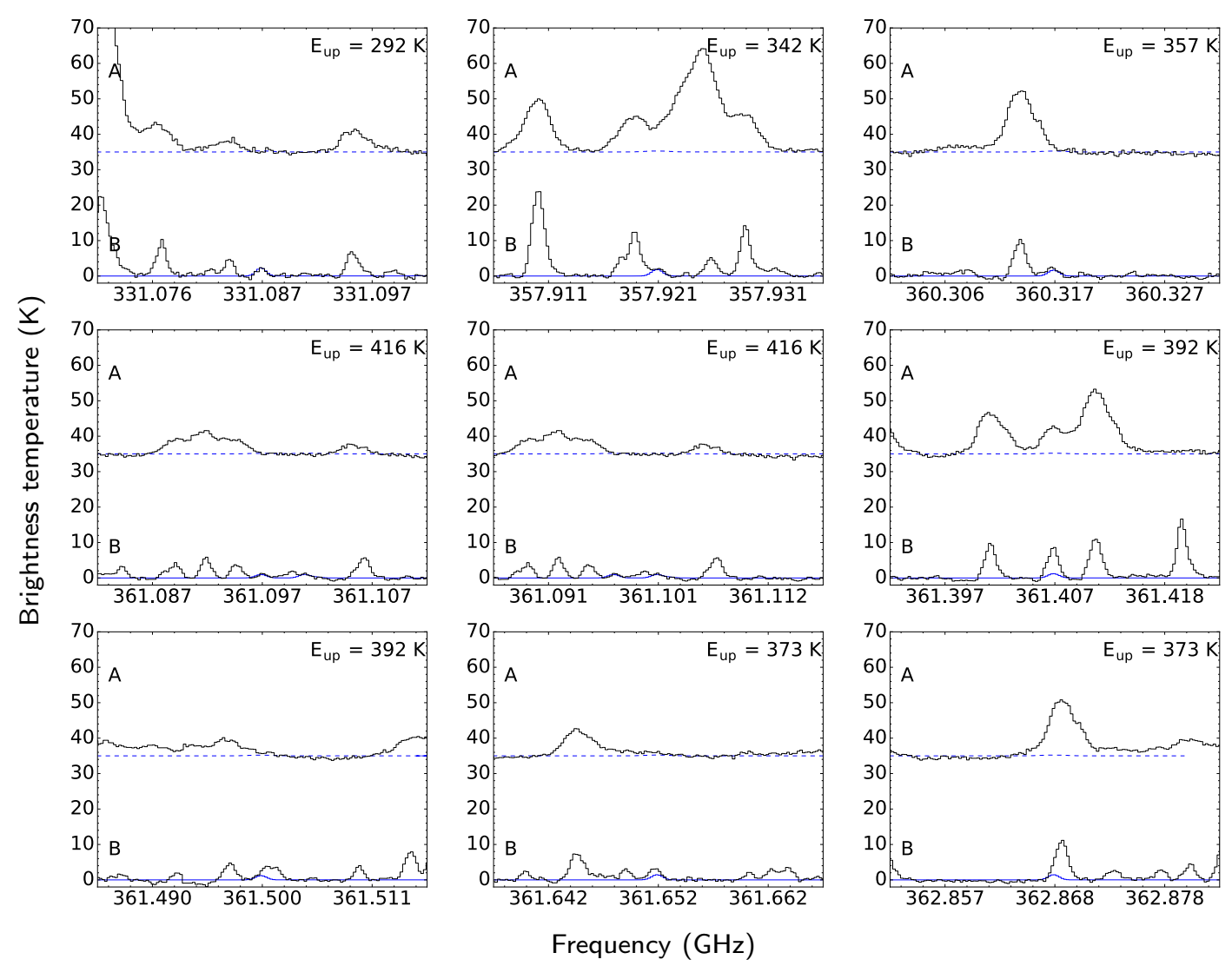

Fig. A.8. Nine brightest lines of $\mathrm{C}_{2} \mathrm{H}_{3} \mathrm{CN}$ detected in IRAS 16293A and IRAS 16293B overlaid with an LTE spectral model of the emission in each source. Source A is offset by $35 \mathrm{~K}$ on the $y$-axis.

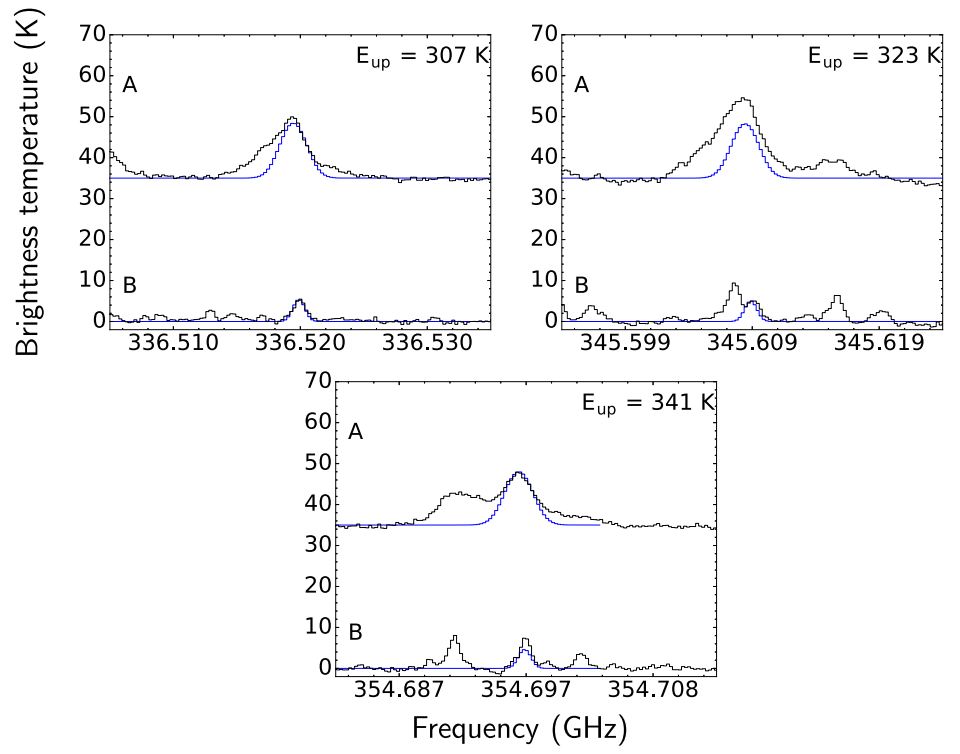

Fig. A.9. Three lines of $\mathrm{HC}_{3} \mathrm{~N}$ detected in IRAS $16293 \mathrm{~A}$ and IRAS 16293B overlaid with an LTE spectral model of the emission in each source. Source A is offset by $35 \mathrm{~K}$ on the $y$-axis. 


\section{Appendix B: Transitional information}

Transitional information for all of the lines detected $(>3 \sigma)$ in this work.

Table B.1. Detected lines of $\mathrm{CH}_{3} \mathrm{CN} v_{8}=1$.

\begin{tabular}{lccccc}
\hline \hline Transitions & $\begin{array}{c}\text { Frequency } \\
(\mathrm{MHz})\end{array}$ & $\begin{array}{c}E_{\mathrm{up}} \\
(\mathrm{K})\end{array}$ & $\begin{array}{c}A_{\mathrm{ij}} \\
\left(\mathrm{s}^{-1}\right)\end{array}$ & Blended A $^{a}$ & Blended B $^{a}$ \\
\hline $18-13-1713$ & 331748.52 & 670 & $3.14 \times 10^{-3}$ & $\mathrm{Y}$ & $\mathrm{Y}$ \\
$18-22-1722$ & 331992.35 & 732 & $3.12 \times 10^{-3}$ & $\mathrm{Y}$ & $\mathrm{N}$ \\
$1822-17-22$ & 331992.35 & 732 & $3.12 \times 10^{-3}$ & $\mathrm{Y}$ & $\mathrm{N}$ \\
$1802-1702$ & 332015.82 & 677 & $3.16 \times 10^{-3}$ & $\mathrm{Y}$ & $\mathrm{Y}$ \\
$18-43-1743$ & 332028.76 & 738 & $3.00 \times 10^{-3}$ & $\mathrm{Y}$ & $\mathrm{N}$ \\
$1843-17-43$ & 332028.76 & 738 & $3.00 \times 10^{-3}$ & $\mathrm{Y}$ & $\mathrm{N}$ \\
$1823-1723$ & 332107.65 & 679 & $3.12 \times 10^{-3}$ & $\mathrm{Y}$ & $\mathrm{Y}$ \\
$1813-17-13$ & 332387.75 & 671 & $3.16 \times 10^{-3}$ & $\mathrm{~N}$ & $\mathrm{~N}$ \\
$1913-18-13$ & 350168.10 & 687 & $3.70 \times 10^{-3}$ & $\mathrm{~N}$ & $\mathrm{~N}$ \\
$19-22-1822$ & 350423.62 & 749 & $3.68 \times 10^{-3}$ & $\mathrm{Y}$ & $\mathrm{N}$ \\
$1922-18-22$ & 350423.62 & 749 & $3.68 \times 10^{-3}$ & $\mathrm{Y}$ & $\mathrm{N}$ \\
$1902-1802$ & 350444.91 & 693 & $3.72 \times 10^{-3}$ & $\mathrm{Y}$ & $\mathrm{Y}$ \\
$19-43-1843$ & 350465.65 & 754 & $3.56 \times 10^{-3}$ & $\mathrm{Y}$ & $\mathrm{Y}$ \\
$1943-18-43$ & 350465.65 & 754 & $3.56 \times 10^{-3}$ & $\mathrm{Y}$ & $\mathrm{Y}$ \\
$19-13-1813$ & 350842.67 & 687 & $3.72 \times 10^{-3}$ & $\mathrm{Y}$ & $\mathrm{Y}$ \\
\hline
\end{tabular}

Notes. ${ }^{(a)}$ Y means line is blended with another molecule.

Table B.2. Detected lines of ${ }^{13} \mathrm{CH}_{3} \mathrm{CN}$.

\begin{tabular}{cccccc}
\hline \hline Transitions & $\begin{array}{c}\text { Frequency } \\
(\mathrm{MHz})\end{array}$ & $\begin{array}{c}E_{\mathrm{up}} \\
(\mathrm{K})\end{array}$ & $\begin{array}{c}A_{\mathrm{ij}} \\
\left(\mathrm{s}^{-1}\right)\end{array}$ & Blended A $^{a}$ & Blended B $^{a}$ \\
\hline $196-186$ & 339137.34 & 420 & $3.06 \times 10^{-3}$ & $\mathrm{Y}$ & $\mathrm{Y}$ \\
$195-185$ & 339207.24 & 342 & $3.17 \times 10^{-3}$ & $\mathrm{Y}$ & $\mathrm{Y}$ \\
$194-184$ & 339264.47 & 277 & $3.25 \times 10^{-3}$ & $\mathrm{~N}$ & $\mathrm{~N}$ \\
$193-183$ & 339309.01 & 227 & $3.32 \times 10^{-3}$ & $\mathrm{Y}$ & $\mathrm{N}$ \\
$192-182$ & 339340.83 & 192 & $3.37 \times 10^{-3}$ & $\mathrm{~N}$ & $\mathrm{~N}$ \\
$191-181$ & 339359.93 & 170 & $3.40 \times 10^{-3}$ & $\mathrm{~N}$ & $\mathrm{~N}$ \\
$190-180$ & 339366.30 & 163 & $3.41 \times 10^{-3}$ & $\mathrm{~N}$ & $\mathrm{~N}$ \\
$206-196$ & 356975.47 & 437 & $3.61 \times 10^{-3}$ & $\mathrm{Y}$ & $\mathrm{N}$ \\
$205-195$ & 357049.02 & 359 & $3.73 \times 10^{-3}$ & $\mathrm{Y}$ & $\mathrm{Y}$ \\
$204-194$ & 357109.23 & 294 & $3.82 \times 10^{-3}$ & $\mathrm{Y}$ & $\mathrm{N}$ \\
$203-193$ & 357156.09 & 244 & $3.89 \times 10^{-3}$ & $\mathrm{Y}$ & $\mathrm{N}$ \\
$202-192$ & 357189.58 & 209 & $3.94 \times 10^{-3}$ & $\mathrm{Y}$ & $\mathrm{N}$ \\
$201-191$ & 357209.67 & 187 & $3.97 \times 10^{-3}$ & $\mathrm{Y}$ & $\mathrm{N}$ \\
$200-190$ & 357216.37 & 180 & $3.98 \times 10^{-3}$ & $\mathrm{~N}$ & $\mathrm{~N}$ \\
\hline
\end{tabular}

Notes. ${ }^{(a)}$ Y means line is blended with another molecule. 
Table B.3. Detected lines of $\mathrm{CH}_{3}{ }^{13} \mathrm{CN}$.

\begin{tabular}{cccccc}
\hline \hline Transitions & $\begin{array}{c}\text { Frequency } \\
(\mathrm{MHz})\end{array}$ & $\begin{array}{c}E_{\mathrm{up}} \\
(\mathrm{K})\end{array}$ & $\begin{array}{c}A_{\mathrm{ij}} \\
\left(\mathrm{s}^{-1}\right)\end{array}$ & Blended A $^{a}$ & Blended B $^{a}$ \\
\hline $186-176$ & 330679.89 & 408 & $2.80 \times 10^{-3}$ & $\mathrm{~N}$ & $\mathrm{~N}$ \\
$185-175$ & 330749.43 & 329 & $2.91 \times 10^{-3}$ & $\mathrm{~N}$ & $\mathrm{~N}$ \\
$184-174$ & 330806.40 & 265 & $3.00 \times 10^{-3}$ & $\mathrm{Y}$ & $\mathrm{Y}$ \\
$183-173$ & 330850.71 & 215 & $3.07 \times 10^{-3}$ & $\mathrm{Y}$ & $\mathrm{Y}$ \\
$182-172$ & 330882.40 & 179 & $3.12 \times 10^{-3}$ & $\mathrm{~N}$ & $\mathrm{~N}$ \\
$181-171$ & 330901.39 & 158 & $3.15 \times 10^{-3}$ & $\mathrm{~N}$ & $\mathrm{~N}$ \\
$180-170$ & 330907.73 & 151 & $3.16 \times 10^{-3}$ & $\mathrm{Y}$ & $\mathrm{N}$ \\
$196-186$ & 349040.38 & 425 & $3.34 \times 10^{-3}$ & $\mathrm{Y}$ & $\mathrm{N}$ \\
$195-185$ & 349113.77 & 346 & $3.45 \times 10^{-3}$ & $\mathrm{Y}$ & $\mathrm{Y}$ \\
$194-184$ & 349173.86 & 282 & $3.55 \times 10^{-3}$ & $\mathrm{Y}$ & $\mathrm{Y}$ \\
$193-183$ & 349220.62 & 232 & $3.62 \times 10^{-3}$ & $\mathrm{~N}$ & $\mathrm{~N}$ \\
$192-182$ & 349254.03 & 196 & $3.67 \times 10^{-3}$ & $\mathrm{~N}$ & $\mathrm{~N}$ \\
$191-181$ & 349274.09 & 175 & $3.71 \times 10^{-3}$ & $\mathrm{~N}$ & $\mathrm{~N}$ \\
$190-180$ & 349280.77 & 168 & $3.72 \times 10^{-3}$ & $\mathrm{Y}$ & $\mathrm{N}$ \\
\hline
\end{tabular}

Notes. ${ }^{(a)}$ Y means line is blended with another molecule.

Table B.4. Detected lines of $\mathrm{CH}_{3} \mathrm{C}^{15} \mathrm{~N}$

\begin{tabular}{cccccc}
\hline \hline Transitions & $\begin{array}{c}\text { Frequency } \\
(\mathrm{MHz})\end{array}$ & $\begin{array}{c}E_{\mathrm{up}} \\
(\mathrm{K})\end{array}$ & $\begin{array}{c}A_{\mathrm{ij}} \\
\left(\mathrm{s}^{-1}\right)\end{array}$ & Blended A $^{a}$ & Blended B $^{a}$ \\
\hline $196-186$ & 338710.02 & 420 & $3.06 \times 10^{-3}$ & $\mathrm{Y}$ & $\mathrm{Y}$ \\
$195-185$ & 338780.22 & 342 & $3.16 \times 10^{-3}$ & $\mathrm{Y}$ & $\mathrm{N}$ \\
$194-184$ & 338837.68 & 277 & $3.25 \times 10^{-3}$ & $\mathrm{~N}$ & $\mathrm{~N}$ \\
$193-183$ & 338882.39 & 227 & $3.32 \times 10^{-3}$ & $\mathrm{Y}$ & $\mathrm{Y}$ \\
$192-182$ & 338914.34 & 191 & $3.36 \times 10^{-3}$ & $\mathrm{Y}$ & $\mathrm{Y}$ \\
$191-181$ & 338933.54 & 170 & $3.39 \times 10^{-3}$ & $\mathrm{Y}$ & $\mathrm{Y}$ \\
$190-180$ & 338939.93 & 163 & $3.40 \times 10^{-3}$ & $\mathrm{~N}$ & $\mathrm{~N}$ \\
$206-196$ & 356525.88 & 437 & $3.61 \times 10^{-3}$ & $\mathrm{Y}$ & $\mathrm{Y}$ \\
$205-195$ & 356599.73 & 359 & $3.72 \times 10^{-3}$ & $\mathrm{Y}$ & $\mathrm{Y}$ \\
$204-194$ & 356660.20 & 294 & $3.81 \times 10^{-3}$ & $\mathrm{Y}$ & $\mathrm{Y}$ \\
$203-193$ & 356707.25 & 244 & $3.88 \times 10^{-3}$ & $\mathrm{Y}$ & $\mathrm{Y}$ \\
$202-192$ & 356740.87 & 208 & $3.93 \times 10^{-3}$ & $\mathrm{Y}$ & $\mathrm{Y}$ \\
$201-191$ & 356761.05 & 187 & $3.96 \times 10^{-3}$ & $\mathrm{Y}$ & $\mathrm{Y}$ \\
$200-190$ & 356767.77 & 180 & $3.97 \times 10^{-3}$ & $\mathrm{~N}$ & $\mathrm{~N}$ \\
\hline
\end{tabular}

Notes. ${ }^{(a)}$ Y means line is blended with another molecule. 
Table B.5. Detected lines of $\mathrm{CH}_{2} \mathrm{DCN}$.

\begin{tabular}{|c|c|c|c|c|c|}
\hline Transitions & $\begin{array}{c}\text { Frequency } \\
(\mathrm{MHz})\end{array}$ & $\begin{array}{l}E_{\text {up }} \\
(\mathrm{K})\end{array}$ & $\begin{array}{c}A_{\mathrm{ij}} \\
\left(\mathrm{s}^{-1}\right) \\
\end{array}$ & Blended $\mathrm{A}^{a}$ & Blended $\mathrm{B}^{a}$ \\
\hline CH2DCN $19811-18810$ & 329548.11 & 503 & $2.57 \times 10^{-3}$ & $\mathrm{~N}$ & $\mathrm{~N}$ \\
\hline CH2DCN $19812-18811$ & 329548.11 & 503 & $2.57 \times 10^{-3}$ & $\mathrm{~N}$ & $\mathrm{~N}$ \\
\hline CH2DCN $19713-18712$ & 329630.28 & 422 & $2.70 \times 10^{-3}$ & $\mathrm{Y}$ & $\mathrm{N}$ \\
\hline CH2DCN $19712-18711$ & 329630.28 & 422 & $2.70 \times 10^{-3}$ & Y & $\mathrm{N}$ \\
\hline CH2DCN $19613-18612$ & 329702.08 & 352 & $2.81 \times 10^{-3}$ & $\mathrm{Y}$ & $\mathrm{N}$ \\
\hline CH2DCN $19614-18613$ & 329702.08 & 352 & $2.81 \times 10^{-3}$ & $\mathrm{Y}$ & $\mathrm{N}$ \\
\hline CH2DCN $19019-18018$ & 329720.02 & 158 & $3.12 \times 10^{-3}$ & $\mathrm{~N}$ & $\mathrm{~N}$ \\
\hline CH2DCN $19514-18513$ & 329763.98 & 293 & $2.91 \times 10^{-3}$ & $\mathrm{~N}$ & $\mathrm{~N}$ \\
\hline CH2DCN $19515-18514$ & 329763.98 & 293 & $2.91 \times 10^{-3}$ & $\mathrm{~N}$ & $\mathrm{~N}$ \\
\hline CH2DCN $19416-18415$ & 329817.09 & 245 & $2.99 \times 10^{-3}$ & $\mathrm{Y}$ & Y \\
\hline CH2DCN $19415-18414$ & 329817.10 & 245 & $2.99 \times 10^{-3}$ & $\mathrm{Y}$ & $\mathrm{Y}$ \\
\hline CH2DCN $19218-18217$ & 329842.21 & 180 & $3.09 \times 10^{-3}$ & $\mathrm{~N}$ & $\mathrm{~N}$ \\
\hline CH2DCN $19317-18316$ & 329864.19 & 207 & $3.05 \times 10^{-3}$ & $\mathrm{Y}$ & $\mathrm{N}$ \\
\hline CH2DCN $19316-18315$ & 329866.11 & 207 & $3.05 \times 10^{-3}$ & $\mathrm{Y}$ & $\mathrm{N}$ \\
\hline CH2DCN $19217-18216$ & 330013.79 & 180 & $3.10 \times 10^{-3}$ & $\mathrm{Y}$ & $\mathrm{Y}$ \\
\hline CH2DCN $19118-18117$ & 331271.79 & 164 & $3.16 \times 10^{-3}$ & $\mathrm{~N}$ & $\mathrm{~N}$ \\
\hline CH2DCN $20120-19119$ & 345685.38 & 180 & $3.60 \times 10^{-3}$ & $\mathrm{Y}$ & $\mathrm{N}$ \\
\hline CH2DCN $20813-19812$ & 346882.40 & 520 & $3.06 \times 10^{-3}$ & $\mathrm{Y}$ & $\mathrm{N}$ \\
\hline CH2DCN $20812-19811$ & 346882.40 & 520 & $3.06 \times 10^{-3}$ & $\mathrm{Y}$ & $\mathrm{N}$ \\
\hline CH2DCN $20713-19712$ & 346968.95 & 439 & $3.20 \times 10^{-3}$ & $\mathrm{Y}$ & $\mathrm{N}$ \\
\hline CH2DCN $20714-19713$ & 346968.95 & 439 & $3.20 \times 10^{-3}$ & Y & $\mathrm{N}$ \\
\hline CH2DCN $20020-19019$ & 347043.46 & 175 & $3.65 \times 10^{-3}$ & $\mathrm{Y}$ & $\mathrm{Y}$ \\
\hline CH2DCN $20614-19613$ & 347044.65 & 369 & $3.32 \times 10^{-3}$ & $\mathrm{Y}$ & Y \\
\hline CH2DCN $20615-19614$ & 347044.65 & 369 & $3.32 \times 10^{-3}$ & $\mathrm{Y}$ & Y \\
\hline CH2DCN $20515-19514$ & 347110.03 & 310 & $3.42 \times 10^{-3}$ & $\mathrm{~N}$ & $\mathrm{~N}$ \\
\hline CH2DCN $20516-19515$ & 347110.03 & 310 & $3.42 \times 10^{-3}$ & $\mathrm{~N}$ & $\mathrm{~N}$ \\
\hline CH2DCN $20417-19416$ & 347166.41 & 261 & $3.50 \times 10^{-3}$ & $\mathrm{~N}$ & $\mathrm{~N}$ \\
\hline CH2DCN $20416-19415$ & 347166.42 & 261 & $3.50 \times 10^{-3}$ & $\mathrm{~N}$ & $\mathrm{~N}$ \\
\hline CH2DCN $20219-19218$ & 347188.25 & 197 & $3.61 \times 10^{-3}$ & $\mathrm{~N}$ & $\mathrm{~N}$ \\
\hline CH2DCN $20318-19317$ & 347216.88 & 224 & $3.57 \times 10^{-3}$ & $\mathrm{Y}$ & $\mathrm{N}$ \\
\hline CH2DCN $20317-19316$ & 347219.36 & 224 & $3.57 \times 10^{-3}$ & $\mathrm{Y}$ & $\mathrm{N}$ \\
\hline CH2DCN $20218-19217$ & 347388.25 & 197 & $3.62 \times 10^{-3}$ & $\mathrm{~N}$ & $\mathrm{~N}$ \\
\hline CH2DCN $20119-19118$ & 348690.94 & 181 & $3.69 \times 10^{-3}$ & $\mathrm{~N}$ & $\mathrm{~N}$ \\
\hline
\end{tabular}

Notes. ${ }^{(a)}$ Y means line is blended with another molecule. 
Table B.6. Detected lines of $\mathrm{CHD}_{2} \mathrm{CN}$.

\begin{tabular}{|c|c|c|c|c|c|}
\hline Transitions & $\begin{array}{c}\text { Frequency } \\
(\mathrm{MHz})\end{array}$ & $\begin{array}{l}E_{\text {up }} \\
(\mathrm{K})\end{array}$ & $\begin{array}{c}A_{\mathrm{ij}} \\
\left(\mathrm{s}^{-1}\right)\end{array}$ & Blended $\mathrm{A}^{a}$ & Blended $\mathrm{B}^{a}$ \\
\hline CHD2CN $20020-19019$ & 329318.90 & 166 & $3.12 \times 10^{-3}$ & $\mathrm{~N}$ & $\mathrm{~N}$ \\
\hline CHD2CN $20516-19515$ & 329476.66 & 272 & $2.93 \times 10^{-3}$ & Y & Y \\
\hline CHD2CN $20515-19514$ & 329476.66 & 272 & $2.93 \times 10^{-3}$ & $\mathrm{Y}$ & Y \\
\hline CHD2CN $20219-19218$ & 329526.16 & 183 & $3.09 \times 10^{-3}$ & $\mathrm{Y}$ & $\mathrm{Y}$ \\
\hline CHD2CN $20417-19416$ & 329528.91 & 234 & $3.00 \times 10^{-3}$ & $\mathrm{Y}$ & $\mathrm{Y}$ \\
\hline CHD2CN $20416-19415$ & 329528.94 & 234 & $3.00 \times 10^{-3}$ & $\mathrm{Y}$ & $\mathrm{Y}$ \\
\hline CHD2CN $20318-19317$ & 329578.05 & 204 & $3.05 \times 10^{-3}$ & $\mathrm{Y}$ & $\mathrm{N}$ \\
\hline CHD2CN $20317-19316$ & 329582.49 & 204 & $3.05 \times 10^{-3}$ & Y & $\mathrm{N}$ \\
\hline CHD2CN $20218-19217$ & 329797.26 & 183 & $3.10 \times 10^{-3}$ & $\mathrm{Y}$ & $\mathrm{N}$ \\
\hline CHD2CN $20119-19118$ & 331070.43 & 171 & $3.16 \times 10^{-3}$ & $\mathrm{Y}$ & $\mathrm{Y}$ \\
\hline CHD2CN $21121-20120$ & 344345.88 & 186 & $3.56 \times 10^{-3}$ & $\mathrm{Y}$ & $\mathrm{N}$ \\
\hline CHD2CN $21021-20020$ & 345745.31 & 183 & $3.61 \times 10^{-3}$ & Y & $\mathrm{N}$ \\
\hline CHD2CN $21516-20515$ & 345941.09 & 289 & $3.41 \times 10^{-3}$ & $\mathrm{Y}$ & $\mathrm{Y}$ \\
\hline CHD2CN $21517-20516$ & 345941.09 & 289 & $3.41 \times 10^{-3}$ & $\mathrm{Y}$ & $\mathrm{Y}$ \\
\hline CHD2CN $21220-20219$ & 345986.91 & 200 & $3.59 \times 10^{-3}$ & $\mathrm{Y}$ & $\mathrm{Y}$ \\
\hline CHD2CN $21418-20417$ & 345996.67 & 250 & $3.49 \times 10^{-3}$ & $\mathrm{Y}$ & $\mathrm{Y}$ \\
\hline CHD2CN $21417-20416$ & 345996.71 & 250 & $3.49 \times 10^{-3}$ & Y & Y \\
\hline CHD2CN $21319-20318$ & 346049.48 & 221 & $3.55 \times 10^{-3}$ & $\mathrm{~N}$ & $\mathrm{~N}$ \\
\hline CHD2CN $21318-20317$ & 346055.14 & 221 & $3.55 \times 10^{-3}$ & $\mathrm{~N}$ & $\mathrm{~N}$ \\
\hline CHD2CN $21219-20218$ & 346300.34 & 200 & $3.60 \times 10^{-3}$ & $\mathrm{~N}$ & $\mathrm{~N}$ \\
\hline CHD2CN $21120-20119$ & 347605.22 & 188 & $3.66 \times 10^{-3}$ & $\mathrm{Y}$ & $\mathrm{Y}$ \\
\hline CHD2CN $22122-21121$ & 360724.24 & 203 & $4.10 \times 10^{-3}$ & $\mathrm{Y}$ & $\mathrm{Y}$ \\
\hline CHD2CN $22022-21021$ & 362166.08 & 200 & $4.15 \times 10^{-3}$ & $\mathrm{~N}$ & $\mathrm{~N}$ \\
\hline CHD2CN $22617-21616$ & 362338.39 & 352 & $3.85 \times 10^{-3}$ & $\mathrm{Y}$ & $\mathrm{Y}$ \\
\hline CHD2CN $22616-21615$ & 362338.39 & 352 & $3.85 \times 10^{-3}$ & $\mathrm{Y}$ & $\mathrm{Y}$ \\
\hline CHD2CN $22518-21517$ & 362404.16 & 306 & $3.95 \times 10^{-3}$ & $\mathrm{~N}$ & $\mathrm{~N}$ \\
\hline CHD2CN $22517-21516$ & 362404.16 & 306 & $3.95 \times 10^{-3}$ & $\mathrm{~N}$ & $\mathrm{~N}$ \\
\hline CHD2CN $22221-21220$ & 362445.39 & 217 & $4.13 \times 10^{-3}$ & $\mathrm{~N}$ & $\mathrm{~N}$ \\
\hline CHD2CN $22419-21418$ & 362463.16 & 268 & $4.03 \times 10^{-3}$ & $\mathrm{Y}$ & $\mathrm{N}$ \\
\hline CHD2CN $22418-21417$ & 362463.22 & 268 & $4.03 \times 10^{-3}$ & $\mathrm{Y}$ & $\mathrm{N}$ \\
\hline CHD2CN $22320-21319$ & 362519.76 & 238 & $4.09 \times 10^{-3}$ & $\mathrm{Y}$ & $\mathrm{Y}$ \\
\hline CHD2CN $22319-21318$ & 362526.91 & 238 & $4.09 \times 10^{-3}$ & $\mathrm{Y}$ & $\mathrm{Y}$ \\
\hline CHD2CN $22220-21219$ & 362805.20 & 217 & $4.14 \times 10^{-3}$ & $\mathrm{Y}$ & $\mathrm{N}$ \\
\hline
\end{tabular}

Notes. ${ }^{(a)}$ Y means line is blended with another molecule. 
Table B.7. Detected lines of $\mathrm{C}_{2} \mathrm{H}_{5} \mathrm{CN}$.

\begin{tabular}{|c|c|c|c|c|c|}
\hline Transitions & $\begin{array}{c}\text { Frequency } \\
(\mathrm{MHz})\end{array}$ & $\begin{array}{l}E_{\text {up }} \\
(\mathrm{K})\end{array}$ & $\begin{array}{c}A_{\mathrm{ij}} \\
\left(\mathrm{s}^{-1}\right)\end{array}$ & Blended $\mathrm{A}^{a}$ & Blended $\mathrm{B}^{a}$ \\
\hline $36333-35332$ & 329234.72 & 301 & $3.02 \times 10^{-3}$ & $\mathrm{~N}$ & $\mathrm{~N}$ \\
\hline $38237-37236$ & 331439.54 & 318 & $3.09 \times 10^{-3}$ & $\mathrm{Y}$ & $\mathrm{N}$ \\
\hline $371225-361224$ & 331484.52 & 462 & $2.77 \times 10^{-3}$ & $\mathrm{Y}$ & $\mathrm{Y}$ \\
\hline $371226-361225$ & 331484.52 & 462 & $2.77 \times 10^{-3}$ & $\mathrm{Y}$ & $\mathrm{N}$ \\
\hline $371126-361125$ & 331487.29 & 437 & $2.83 \times 10^{-3}$ & $\mathrm{Y}$ & $\mathrm{Y}$ \\
\hline $371127-361126$ & 331487.29 & 437 & $2.83 \times 10^{-3}$ & $\mathrm{Y}$ & $\mathrm{Y}$ \\
\hline $371324-361323$ & 331506.93 & 490 & $2.72 \times 10^{-3}$ & $\mathrm{Y}$ & $\mathrm{N}$ \\
\hline $371325-361324$ & 331506.93 & 490 & $2.72 \times 10^{-3}$ & $\mathrm{Y}$ & $\mathrm{N}$ \\
\hline $371028-361027$ & 331523.32 & 413 & $2.88 \times 10^{-3}$ & $\mathrm{Y}$ & $\mathrm{Y}$ \\
\hline $371027-361026$ & 331523.32 & 413 & $2.88 \times 10^{-3}$ & $\mathrm{Y}$ & $\mathrm{Y}$ \\
\hline $371424-361423$ & 331549.42 & 520 & $2.66 \times 10^{-3}$ & $\mathrm{~N}$ & $\mathrm{~N}$ \\
\hline $371423-361422$ & 331549.42 & 520 & $2.66 \times 10^{-3}$ & $\mathrm{~N}$ & $\mathrm{~N}$ \\
\hline $37929-36928$ & 331605.59 & 392 & $2.92 \times 10^{-3}$ & $\mathrm{Y}$ & $\mathrm{N}$ \\
\hline $37928-36927$ & 331605.59 & 392 & $2.92 \times 10^{-3}$ & $\mathrm{Y}$ & $\mathrm{N}$ \\
\hline $37235-36234$ & 331662.29 & 311 & $3.08 \times 10^{-3}$ & $\mathrm{~N}$ & $\mathrm{~N}$ \\
\hline $38137-37136$ & 331748.53 & 318 & $3.09 \times 10^{-3}$ & $\mathrm{Y}$ & $\mathrm{Y}$ \\
\hline $37829-36828$ & 331756.44 & 373 & $2.96 \times 10^{-3}$ & $\mathrm{Y}$ & $\mathrm{Y}$ \\
\hline $37830-36829$ & 331756.44 & 373 & $2.96 \times 10^{-3}$ & $\mathrm{Y}$ & $\mathrm{Y}$ \\
\hline $37731-36730$ & 332014.73 & 357 & $3.00 \times 10^{-3}$ & $\mathrm{Y}$ & $\mathrm{Y}$ \\
\hline $37730-36729$ & 332020.59 & 357 & $3.00 \times 10^{-3}$ & $\mathrm{Y}$ & $\mathrm{Y}$ \\
\hline $37434-36433$ & 332126.30 & 321 & $3.08 \times 10^{-3}$ & $\mathrm{Y}$ & $\mathrm{N}$ \\
\hline $37632-36631$ & 332428.04 & 343 & $3.04 \times 10^{-3}$ & $\mathrm{Y}$ & $\mathrm{N}$ \\
\hline $37631-36630$ & 332529.86 & 343 & $3.05 \times 10^{-3}$ & $\mathrm{Y}$ & $\mathrm{Y}$ \\
\hline $37533-36532$ & 332830.71 & 331 & $3.08 \times 10^{-3}$ & $\mathrm{Y}$ & $\mathrm{N}$ \\
\hline $39139-38138$ & 333265.90 & 323 & $3.15 \times 10^{-3}$ & $\mathrm{Y}$ & $\mathrm{N}$ \\
\hline $39039-38038$ & 333274.67 & 323 & $3.15 \times 10^{-3}$ & $\mathrm{Y}$ & $\mathrm{N}$ \\
\hline $37532-36531$ & 333921.55 & 331 & $3.11 \times 10^{-3}$ & $\mathrm{~N}$ & $\mathrm{~N}$ \\
\hline $38336-37335$ & 337347.58 & 328 & $3.24 \times 10^{-3}$ & $\mathrm{Y}$ & $\mathrm{Y}$ \\
\hline $37433-36432$ & 337445.86 & 322 & $3.23 \times 10^{-3}$ & $\mathrm{Y}$ & $\mathrm{Y}$ \\
\hline $37334-36333$ & 338142.85 & 317 & $3.27 \times 10^{-3}$ & $\mathrm{Y}$ & Y \\
\hline $39238-38237$ & 339894.69 & 334 & $3.33 \times 10^{-3}$ & $\mathrm{~N}$ & $\mathrm{~N}$ \\
\hline $38236-37235$ & 339968.22 & 327 & $3.32 \times 10^{-3}$ & $\mathrm{~N}$ & $\mathrm{~N}$ \\
\hline $39138-38137$ & 340149.11 & 334 & $3.34 \times 10^{-3}$ & $\mathrm{~N}$ & $\mathrm{~N}$ \\
\hline $381226-371225$ & 340432.64 & 478 & $3.02 \times 10^{-3}$ & $\mathrm{~N}$ & $\mathrm{~N}$ \\
\hline $381227-371226$ & 340432.64 & 478 & $3.02 \times 10^{-3}$ & $\mathrm{~N}$ & $\mathrm{~N}$ \\
\hline $381127-371126$ & 340440.07 & 453 & $3.08 \times 10^{-3}$ & $\mathrm{Y}$ & $\mathrm{Y}$ \\
\hline $381128-371127$ & 340440.07 & 453 & $3.08 \times 10^{-3}$ & $\mathrm{Y}$ & $\mathrm{Y}$ \\
\hline $381325-371324$ & 340452.19 & 506 & $2.97 \times 10^{-3}$ & $\mathrm{Y}$ & $\mathrm{Y}$ \\
\hline $381326-371325$ & 340452.19 & 506 & $2.97 \times 10^{-3}$ & $\mathrm{Y}$ & $\mathrm{Y}$ \\
\hline $381029-371028$ & 340483.19 & 430 & $3.13 \times 10^{-3}$ & $\mathrm{Y}$ & $\mathrm{Y}$ \\
\hline $381028-371027$ & 340483.19 & 430 & $3.13 \times 10^{-3}$ & $\mathrm{Y}$ & Y \\
\hline $381425-371424$ & 340492.97 & 536 & $2.91 \times 10^{-3}$ & $\mathrm{Y}$ & $\mathrm{Y}$ \\
\hline $381424-371423$ & 340492.97 & 536 & $2.91 \times 10^{-3}$ & $\mathrm{Y}$ & $\mathrm{Y}$ \\
\hline $381524-371523$ & 340551.30 & 568 & $2.84 \times 10^{-3}$ & $\mathrm{~N}$ & $\mathrm{~N}$ \\
\hline $381523-371522$ & 340551.30 & 568 & $2.84 \times 10^{-3}$ & $\mathrm{~N}$ & $\mathrm{~N}$ \\
\hline $38930-37929$ & 340576.00 & 409 & $3.17 \times 10^{-3}$ & $\mathrm{~N}$ & $\mathrm{~N}$ \\
\hline $38929-37928$ & 340576.00 & 409 & $3.17 \times 10^{-3}$ & $\mathrm{~N}$ & $\mathrm{~N}$ \\
\hline $38830-37829$ & 340742.90 & 390 & $3.22 \times 10^{-3}$ & $\mathrm{Y}$ & $\mathrm{Y}$ \\
\hline $38831-37830$ & 340742.90 & 390 & $3.22 \times 10^{-3}$ & $\mathrm{Y}$ & $\mathrm{Y}$ \\
\hline $38435-37434$ & 340972.71 & 337 & $3.34 \times 10^{-3}$ & $\mathrm{~N}$ & $\mathrm{~N}$ \\
\hline $38732-37731$ & 341025.64 & 373 & $3.26 \times 10^{-3}$ & $\mathrm{Y}$ & Y \\
\hline $38731-37730$ & 341033.90 & 373 & $3.26 \times 10^{-3}$ & $\mathrm{~N}$ & $\mathrm{~N}$ \\
\hline $38633-37632$ & 341468.71 & 359 & $3.31 \times 10^{-3}$ & $\mathrm{~N}$ & $\mathrm{~N}$ \\
\hline
\end{tabular}


Table B.7. continued.

\begin{tabular}{|c|c|c|c|c|c|}
\hline Transitions & $\begin{array}{c}\text { Frequency } \\
(\mathrm{MHz})\end{array}$ & $\begin{array}{l}E_{\text {up }} \\
(\mathrm{K})\end{array}$ & $\begin{array}{c}A_{\mathrm{ij}} \\
\left(\mathrm{s}^{-1}\right)\end{array}$ & Blended $\mathrm{A}^{a}$ & Blended $\mathrm{B}^{a}$ \\
\hline $38632-37631$ & 341603.25 & 359 & $3.31 \times 10^{-3}$ & $\mathrm{Y}$ & $\mathrm{Y}$ \\
\hline $40140-39139$ & 341703.65 & 339 & $3.39 \times 10^{-3}$ & $\mathrm{Y}$ & $\mathrm{Y}$ \\
\hline $40040-39039$ & 341710.58 & 339 & $3.39 \times 10^{-3}$ & $\mathrm{Y}$ & $\mathrm{Y}$ \\
\hline $38534-37533$ & 341852.71 & 347 & $3.34 \times 10^{-3}$ & $\mathrm{~N}$ & $\mathrm{~N}$ \\
\hline $15511-14410$ & 342651.89 & 79 & $1.39 \times 10^{-4}$ & $\mathrm{Y}$ & $\mathrm{Y}$ \\
\hline $15510-14411$ & 342677.56 & 79 & $1.39 \times 10^{-4}$ & $\mathrm{Y}$ & $\mathrm{Y}$ \\
\hline $38533-37532$ & 343194.57 & 347 & $3.38 \times 10^{-3}$ & $\mathrm{Y}$ & $\mathrm{N}$ \\
\hline $39337-38336$ & 345921.20 & 344 & $3.50 \times 10^{-3}$ & $\mathrm{Y}$ & $\mathrm{Y}$ \\
\hline $38434-37433$ & 346874.29 & 339 & $3.52 \times 10^{-3}$ & $\mathrm{~N}$ & $\mathrm{~N}$ \\
\hline $38335-37334$ & 346983.83 & 333 & $3.53 \times 10^{-3}$ & $\mathrm{~N}$ & $\mathrm{~N}$ \\
\hline $39237-38236$ & 348260.57 & 344 & $3.57 \times 10^{-3}$ & $\mathrm{Y}$ & $\mathrm{Y}$ \\
\hline $40239-39238$ & 348344.53 & 351 & $3.58 \times 10^{-3}$ & $\mathrm{~N}$ & $\mathrm{~N}$ \\
\hline $40139-39138$ & 348553.31 & 351 & $3.59 \times 10^{-3}$ & $\mathrm{~N}$ & $\mathrm{~N}$ \\
\hline $391227-381226$ & 349379.90 & 495 & $3.29 \times 10^{-3}$ & $\mathrm{~N}$ & $\mathrm{~N}$ \\
\hline $391228-381227$ & 349379.90 & 495 & $3.29 \times 10^{-3}$ & $\mathrm{~N}$ & $\mathrm{~N}$ \\
\hline $391129-381128$ & 349392.34 & 470 & $3.34 \times 10^{-3}$ & $\mathrm{Y}$ & $\mathrm{Y}$ \\
\hline $391128-381127$ & 349392.34 & 470 & $3.34 \times 10^{-3}$ & $\mathrm{Y}$ & $\mathrm{Y}$ \\
\hline $391327-381326$ & 349396.20 & 523 & $3.23 \times 10^{-3}$ & $\mathrm{Y}$ & $\mathrm{Y}$ \\
\hline $391326-381325$ & 349396.20 & 523 & $3.23 \times 10^{-3}$ & $\mathrm{Y}$ & $\mathrm{Y}$ \\
\hline $391425-381424$ & 349435.13 & 553 & $3.17 \times 10^{-3}$ & $\mathrm{~N}$ & $\mathrm{~N}$ \\
\hline $391426-381425$ & 349435.13 & 553 & $3.17 \times 10^{-3}$ & $\mathrm{~N}$ & $\mathrm{~N}$ \\
\hline $391030-381029$ & 349442.94 & 446 & $3.40 \times 10^{-3}$ & $\mathrm{Y}$ & $\mathrm{Y}$ \\
\hline $391029-381028$ & 349442.94 & 446 & $3.40 \times 10^{-3}$ & $\mathrm{Y}$ & Y \\
\hline $39931-38930$ & 349547.01 & 425 & $3.44 \times 10^{-3}$ & $\mathrm{~N}$ & $\mathrm{~N}$ \\
\hline $39930-38929$ & 349547.03 & 425 & $3.44 \times 10^{-3}$ & $\mathrm{~N}$ & $\mathrm{~N}$ \\
\hline $39832-38831$ & 349730.78 & 407 & $3.49 \times 10^{-3}$ & $\mathrm{~N}$ & $\mathrm{~N}$ \\
\hline $39831-38830$ & 349731.30 & 407 & $3.49 \times 10^{-3}$ & $\mathrm{~N}$ & $\mathrm{~N}$ \\
\hline $39436-38435$ & 349796.03 & 354 & $3.61 \times 10^{-3}$ & $\mathrm{Y}$ & $\mathrm{Y}$ \\
\hline $39733-38732$ & 350039.41 & 390 & $3.54 \times 10^{-3}$ & $\mathrm{~N}$ & $\mathrm{~N}$ \\
\hline $39732-38731$ & 350050.91 & 390 & $3.54 \times 10^{-3}$ & $\mathrm{~N}$ & $\mathrm{~N}$ \\
\hline $41141-40140$ & 350139.63 & 356 & $3.65 \times 10^{-3}$ & $\mathrm{Y}$ & $\mathrm{Y}$ \\
\hline $41041-40040$ & 350145.09 & 356 & $3.65 \times 10^{-3}$ & $\mathrm{Y}$ & $\mathrm{Y}$ \\
\hline $39634-38633$ & 350511.72 & 376 & $3.58 \times 10^{-3}$ & $\mathrm{Y}$ & $\mathrm{N}$ \\
\hline $39633-38632$ & 350687.84 & 376 & $3.59 \times 10^{-3}$ & $\mathrm{Y}$ & $\mathrm{Y}$ \\
\hline $39535-38534$ & 350866.40 & 364 & $3.62 \times 10^{-3}$ & $\mathrm{~N}$ & $\mathrm{~N}$ \\
\hline $39534-38533$ & 352500.71 & 364 & $3.67 \times 10^{-3}$ & $\mathrm{~N}$ & $\mathrm{~N}$ \\
\hline $1166-1055$ & 353234.74 & 68 & $2.06 \times 10^{-4}$ & $\mathrm{Y}$ & $\mathrm{N}$ \\
\hline $1165-1056$ & 353234.76 & 68 & $2.06 \times 10^{-4}$ & $\mathrm{Y}$ & $\mathrm{N}$ \\
\hline $40338-39337$ & 354476.66 & 361 & $3.77 \times 10^{-3}$ & $\mathrm{Y}$ & $\mathrm{Y}$ \\
\hline $39336-38335$ & 355755.96 & 350 & $3.81 \times 10^{-3}$ & $\mathrm{~N}$ & $\mathrm{~N}$ \\
\hline $39435-38434$ & 356276.74 & 356 & $3.81 \times 10^{-3}$ & $\mathrm{Y}$ & $\mathrm{Y}$ \\
\hline $40238-39237$ & 356546.15 & 361 & $3.84 \times 10^{-3}$ & $\mathrm{Y}$ & $\mathrm{Y}$ \\
\hline $41240-40239$ & 356789.59 & 368 & $3.85 \times 10^{-3}$ & $\mathrm{Y}$ & $\mathrm{N}$ \\
\hline $41140-40139$ & 356960.42 & 368 & $3.86 \times 10^{-3}$ & $\mathrm{~N}$ & $\mathrm{~N}$ \\
\hline $401229-391228$ & 358326.20 & 512 & $3.57 \times 10^{-3}$ & $\mathrm{~N}$ & $\mathrm{~N}$ \\
\hline $401228-391227$ & 358326.20 & 512 & $3.57 \times 10^{-3}$ & $\mathrm{~N}$ & $\mathrm{~N}$ \\
\hline $401327-391326$ & 358339.01 & 540 & $3.51 \times 10^{-3}$ & $\mathrm{~N}$ & $\mathrm{~N}$ \\
\hline $401328-391327$ & 358339.01 & 540 & $3.51 \times 10^{-3}$ & $\mathrm{~N}$ & $\mathrm{~N}$ \\
\hline $401129-391128$ & 358344.02 & 487 & $3.62 \times 10^{-3}$ & $\mathrm{Y}$ & $\mathrm{Y}$ \\
\hline $401130-391129$ & 358344.02 & 487 & $3.62 \times 10^{-3}$ & $\mathrm{Y}$ & $\mathrm{Y}$ \\
\hline $401427-391426$ & 358375.84 & 570 & $3.44 \times 10^{-3}$ & $\mathrm{~N}$ & $\mathrm{~N}$ \\
\hline $401426-391425$ & 358375.84 & 570 & $3.44 \times 10^{-3}$ & $\mathrm{~N}$ & $\mathrm{~N}$ \\
\hline
\end{tabular}


A\&A 616, A90 (2018)

Table B.7. continued.

\begin{tabular}{lccccc}
\hline \hline Transitions & $\begin{array}{c}\text { Frequency } \\
(\mathrm{MHz})\end{array}$ & $\begin{array}{c}E_{\text {up }} \\
(\mathrm{K})\end{array}$ & $\begin{array}{c}A_{\mathrm{ij}} \\
\left(\mathrm{s}^{-1}\right)\end{array}$ & Blended A $^{a}$ & Blended B $^{a}$ \\
\hline $401031-391030$ & 358402.65 & 464 & $3.68 \times 10^{-3}$ & $\mathrm{Y}$ & $\mathrm{N}$ \\
$401030-391029$ & 358402.65 & 464 & $3.68 \times 10^{-3}$ & $\mathrm{Y}$ & $\mathrm{N}$ \\
$40932-39931$ & 358518.65 & 443 & $3.73 \times 10^{-3}$ & $\mathrm{~N}$ & $\mathrm{~N}$ \\
$40931-39930$ & 358518.67 & 443 & $3.73 \times 10^{-3}$ & $\mathrm{~N}$ & $\mathrm{~N}$ \\
$42142-41141$ & 358573.80 & 373 & $3.92 \times 10^{-3}$ & $\mathrm{Y}$ & $\mathrm{Y}$ \\
$42042-41041$ & 358578.09 & 373 & $3.92 \times 10^{-3}$ & $\mathrm{Y}$ & $\mathrm{Y}$ \\
$40437-39436$ & 358595.53 & 371 & $3.89 \times 10^{-3}$ & $\mathrm{Y}$ & $\mathrm{Y}$ \\
$40833-39832$ & 358720.46 & 424 & $3.78 \times 10^{-3}$ & $\mathrm{Y}$ & $\mathrm{Y}$ \\
$40832-39831$ & 358721.21 & 424 & $3.78 \times 10^{-3}$ & $\mathrm{Y}$ & $\mathrm{Y}$ \\
$40734-39733$ & 359056.12 & 407 & $3.82 \times 10^{-3}$ & $\mathrm{Y}$ & $\mathrm{Y}$ \\
$40733-39732$ & 359071.92 & 407 & $3.82 \times 10^{-3}$ & $\mathrm{~N}$ & $\mathrm{~N}$ \\
$40635-39634$ & 359556.50 & 393 & $3.87 \times 10^{-3}$ & $\mathrm{Y}$ & $\mathrm{Y}$ \\
$40634-39633$ & 359785.04 & 393 & $3.88 \times 10^{-3}$ & $\mathrm{Y}$ & $\mathrm{N}$ \\
$40536-39535$ & 359870.11 & 381 & $3.91 \times 10^{-3}$ & $\mathrm{Y}$ & $\mathrm{Y}$ \\
$17512-16413$ & 360461.27 & 94 & $1.52 \times 10^{-4}$ & $\mathrm{Y}$ & $\mathrm{Y}$ \\
$40535-39534$ & 361840.75 & 382 & $3.97 \times 10^{-3}$ & $\mathrm{~N}$ & $\mathrm{~N}$ \\
$1267-1156$ & 362187.71 & 74 & $2.10 \times 10^{-4}$ & $\mathrm{Y}$ & $\mathrm{Y}$ \\
$1266-1157$ & 362187.75 & 74 & $2.10 \times 10^{-4}$ & $\mathrm{Y}$ & $\mathrm{Y}$ \\
\hline
\end{tabular}

Note. ${ }^{(a)}$ Y means line is blended with another molecule. 
Table B.8. Detected lines of $\mathrm{C}_{2} \mathrm{H}_{3} \mathrm{CN}$.

\begin{tabular}{|c|c|c|c|c|}
\hline Transitions & $\begin{array}{c}\text { Frequency } \\
(\mathrm{MHz})\end{array}$ & $\begin{array}{l}E_{\text {up }} \\
(\mathrm{K})\end{array}$ & $\begin{array}{c}A_{\mathrm{ij}} \\
\left(\mathrm{s}^{-1}\right)\end{array}$ & Blended $\mathrm{B}^{a}$ \\
\hline $36136-35135$ & 329191.68 & 296 & $2.98 \times 10^{-3}$ & $\mathrm{~N}$ \\
\hline $36036-35035$ & 329462.36 & 296 & $2.98 \times 10^{-3}$ & $\mathrm{Y}$ \\
\hline $35134-34133$ & 331086.67 & 292 & $3.02 \times 10^{-3}$ & $\mathrm{~N}$ \\
\hline $35333-34332$ & 332166.70 & 307 & $3.04 \times 10^{-3}$ & $\mathrm{Y}$ \\
\hline $35531-34530$ & 332775.70 & 341 & $3.01 \times 10^{-3}$ & $\mathrm{~N}$ \\
\hline $35432-34431$ & 333047.30 & 322 & $3.04 \times 10^{-3}$ & $\mathrm{Y}$ \\
\hline $35431-34430$ & 333764.56 & 322 & $3.06 \times 10^{-3}$ & $\mathrm{Y}$ \\
\hline $36235-35234$ & 337039.73 & 310 & $3.19 \times 10^{-3}$ & $\mathrm{Y}$ \\
\hline $35332-34331$ & 337050.90 & 308 & $3.17 \times 10^{-3}$ & $\mathrm{Y}$ \\
\hline $37137-36136$ & 338213.51 & 312 & $3.23 \times 10^{-3}$ & $\mathrm{~N}$ \\
\hline $35233-34232$ & 338278.15 & 300 & $3.22 \times 10^{-3}$ & $\mathrm{~N}$ \\
\hline $37037-36036$ & 338447.69 & 312 & $3.24 \times 10^{-3}$ & $\mathrm{~N}$ \\
\hline $36135-35134$ & 340047.92 & 308 & $3.28 \times 10^{-3}$ & $\mathrm{Y}$ \\
\hline $36334-35333$ & 341563.75 & 323 & $3.30 \times 10^{-3}$ & $\mathrm{~N}$ \\
\hline $36631-35630$ & 342052.94 & 381 & $3.25 \times 10^{-3}$ & $\mathrm{~N}$ \\
\hline $36630-35629$ & 342055.21 & 381 & $3.25 \times 10^{-3}$ & $\mathrm{Y}$ \\
\hline $36532-35531$ & 342317.55 & 358 & $3.29 \times 10^{-3}$ & $\mathrm{Y}$ \\
\hline $36531-35530$ & 342375.56 & 358 & $3.29 \times 10^{-3}$ & $\mathrm{Y}$ \\
\hline $36433-35432$ & 342585.47 & 338 & $3.32 \times 10^{-3}$ & $\mathrm{~N}$ \\
\hline $36432-35431$ & 343446.53 & 339 & $3.34 \times 10^{-3}$ & $\mathrm{Y}$ \\
\hline $37236-36235$ & 346184.94 & 326 & $3.45 \times 10^{-3}$ & $\mathrm{Y}$ \\
\hline $36333-35332$ & 346943.07 & 325 & $3.46 \times 10^{-3}$ & $\mathrm{Y}$ \\
\hline $38138-37137$ & 347232.01 & 329 & $3.50 \times 10^{-3}$ & $\mathrm{~N}$ \\
\hline $38038-37037$ & 347434.23 & 329 & $3.50 \times 10^{-3}$ & $\mathrm{~N}$ \\
\hline $36234-35233$ & 347759.03 & 317 & $3.50 \times 10^{-3}$ & $\mathrm{~N}$ \\
\hline $37136-36135$ & 348991.44 & 325 & $3.54 \times 10^{-3}$ & $\mathrm{Y}$ \\
\hline $37335-36334$ & 350947.22 & 340 & $3.59 \times 10^{-3}$ & $\mathrm{Y}$ \\
\hline $37533-36532$ & 351861.48 & 375 & $3.57 \times 10^{-3}$ & $\mathrm{~N}$ \\
\hline $37532-36531$ & 351935.23 & 375 & $3.58 \times 10^{-3}$ & $\mathrm{~N}$ \\
\hline $37434-36433$ & 352120.64 & 355 & $3.61 \times 10^{-3}$ & $\mathrm{Y}$ \\
\hline $37433-36432$ & 353147.23 & 356 & $3.64 \times 10^{-3}$ & $\mathrm{~N}$ \\
\hline $38237-37236$ & 355317.96 & 343 & $3.74 \times 10^{-3}$ & $\mathrm{~N}$ \\
\hline $39139-38138$ & 356247.42 & 346 & $3.78 \times 10^{-3}$ & $\mathrm{Y}$ \\
\hline $39039-38038$ & 356421.72 & 346 & $3.78 \times 10^{-3}$ & $\mathrm{Y}$ \\
\hline $37334-36333$ & 356832.00 & 342 & $3.77 \times 10^{-3}$ & $\mathrm{Y}$ \\
\hline $37235-36234$ & 357202.09 & 334 & $3.80 \times 10^{-3}$ & $\mathrm{Y}$ \\
\hline $38137-37136$ & 357920.91 & 342 & $3.82 \times 10^{-3}$ & $\mathrm{Y}$ \\
\hline $38336-37335$ & 360316.58 & 357 & $3.89 \times 10^{-3}$ & $\mathrm{~N}$ \\
\hline $38633-37632$ & 361097.14 & 416 & $3.84 \times 10^{-3}$ & $\mathrm{~N}$ \\
\hline $38632-37631$ & 361101.24 & 416 & $3.84 \times 10^{-3}$ & $\mathrm{Y}$ \\
\hline $38534-37533$ & 361407.35 & 392 & $3.88 \times 10^{-3}$ & $\mathrm{Y}$ \\
\hline $38533-37532$ & 361500.42 & 392 & $3.88 \times 10^{-3}$ & $\mathrm{Y}$ \\
\hline $38435-37434$ & 361652.04 & 373 & $3.91 \times 10^{-3}$ & $\mathrm{Y}$ \\
\hline
\end{tabular}

Note. ${ }^{(a)}$ Y means line is blended with another molecule.

Table B.9. Detected lines of $\mathrm{HC}_{3} \mathrm{~N}$.

\begin{tabular}{lccccc}
\hline \hline Transitions & $\begin{array}{c}\text { Frequency } \\
(\mathrm{MHz})\end{array}$ & $\begin{array}{c}E_{\mathrm{up}} \\
(\mathrm{K})\end{array}$ & $\begin{array}{c}A_{\mathrm{ij}} \\
\left(\mathrm{s}^{-1}\right)\end{array}$ & Blended A $^{a}$ & Blended B $^{a}$ \\
\hline $37-36$ & 336520.08 & 307 & $3.05 \times 10^{-3}$ & $\mathrm{Y}$ & $\mathrm{N}$ \\
$38-37$ & 345609.01 & 323 & $3.30 \times 10^{-3}$ & $\mathrm{Y}$ & $\mathrm{Y}$ \\
$39-38$ & 354697.00 & 341 & $3.57 \times 10^{-3}$ & $\mathrm{Y}$ & $\mathrm{N}$ \\
\hline
\end{tabular}

Note. ${ }^{(a)}$ Y means line is blended with another molecule. 


\section{Appendix C: Velocity-corrected INtegrated Emission (VINE) maps}

VINE maps of IRAS 16293A.

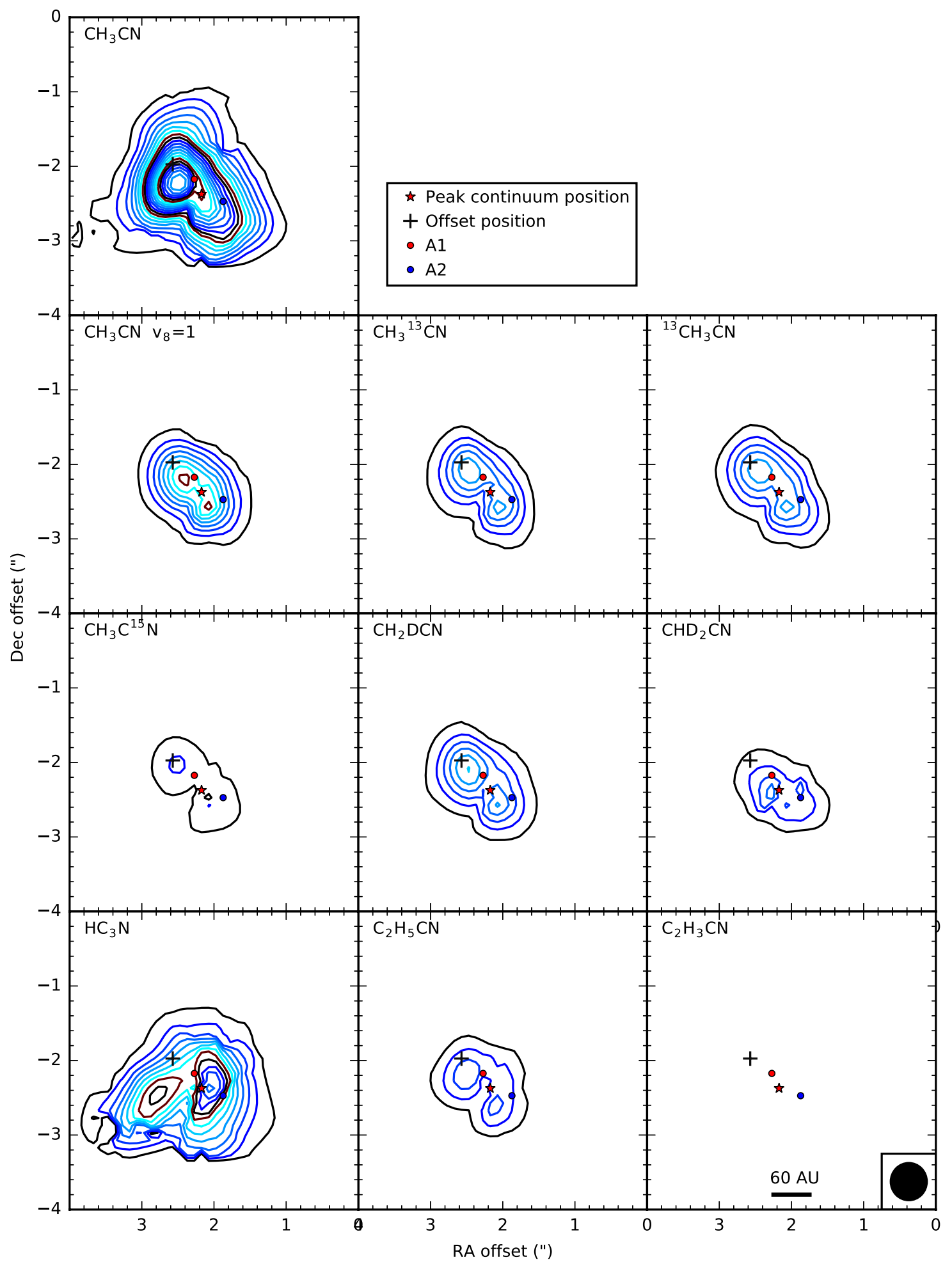

Fig. C.1. VINE maps of IRAS $16293 \mathrm{~A}$ for the $349.346 \mathrm{GHz}$ line of $\mathrm{CH}_{3} \mathrm{CN} v=0$, the $350.168 \mathrm{GHz}$ line of $\mathrm{CH}_{3} \mathrm{CN} v_{8}=1$, the $339.366 \mathrm{GHz}$ line of ${ }^{13} \mathrm{CH}_{3} \mathrm{CN}$, the $349.254 \mathrm{GHz}$ of $\mathrm{CH}_{3}^{13} \mathrm{CN}$, the $338.940 \mathrm{GHz}$ of $\mathrm{CH}_{3} \mathrm{C}^{15} \mathrm{~N}$, the $347.110 \mathrm{GHz}$ of $\mathrm{CH}_{2} \mathrm{DCN}$, the $362.520 \mathrm{GHz}^{-} \mathrm{CHD} \mathrm{CN}$, the $329.235 \mathrm{GHz}$ of $\mathrm{C}_{2} \mathrm{H}_{5} \mathrm{CN}$, the $341.564 \mathrm{GHz}$ of $\mathrm{C}_{2} \mathrm{H}_{3} \mathrm{CN}$ and the $336.520 \mathrm{GHz}$ of $\mathrm{HC}_{3} \mathrm{~N}$. The axis show the position offset from phase centre of the observations. Contour levels start at $80 \mathrm{mJy} \mathrm{km} \mathrm{s}^{-1}$ and increase in steps of $11 \mathrm{mJy} \mathrm{km} \mathrm{s}^{-1}$. The red star marks the peak continuum position in the PILS dataset of IRAS 16293A. The black cross marks the offset position where the spectra analysed in this work are extracted from. The red and blue circles mark the positions of the two continuum peaks A1 and A2 respectively, found by previous authors, using coordinates that have been corrected by the rate of position angle change with year determined by Pech et al. (2010). 